\title{
A Numerical Water Tracer Model for Understanding Event-Scale Hydrometeorological Phenomena
}

\author{
HuAnCUi Hu AND Francina Dominguez \\ Department of Atmospheric Sciences, University of Illinois at Urbana-Champaign, Urbana, Illinois \\ PRAVEEN KUMAR \\ Department of Civil and Environmental Engineering, University of Illinois at Urbana-Champaign, Urbana, Illinois \\ JEFFERY MCDONNELL \\ Global Institute for Water Security, University of Saskatchewan, Saskatoon, Saskatchewan, Canada \\ DAVID GOCHIS \\ National Center for Atmospheric Research, Boulder, Colorado
}

(Manuscript received 31 October 2017, in final form 15 March 2018)

\begin{abstract}
We develop and implement a novel numerical water tracer model within the Noah LSM with multiparameterization options (WT-Noah-MP) that is specifically designed to track individual hydrometeorological events. This approach provides a more complete representation of the physical processes beyond the standard land surface model output. Unlike isotope-enabled LSMs, WT-Noah-MP does not simulate the concentration of oxygen or hydrogen isotopes, or require isotope information to drive it. WT-Noah-MP provides stores, fluxes, and transit time estimates of tagged water in the surface-subsurface system. The new tracer tool can account for the horizontal and vertical heterogeneity of tracer transport in the subsurface by allowing partial mixing in each soil layer. We compared model-estimated transit times at the H. J. Andrews Experimental Watershed in Oregon with those derived from isotope observations. Our results show that including partial mixing in the soil results in a more realistic transit time distribution than the basic well-mixed assumption. We then used WT-Noah-MP to investigate the regional response to an extreme precipitation event in the U.S. Pacific Northwest. The model differentiated the flood response due to direct precipitation from indirect thermal effects and showed that a large portion of this event water was retained in the soil after 6 months. The water tracer addition in Noah-MP can help us quantify the long-term memory in the hydrologic system that can impact seasonal hydroclimate variability through evapotranspiration and groundwater recharge.
\end{abstract}

\section{Introduction}

Land surface models (LSMs) parameterize the exchange of water, energy, and momentum between the land surface and the atmosphere and are a key component in Earth system modeling. The capability of LSMs to capture the timing and extent of the soil water budget, precipitation interception, storage, and eventual loss to either runoff or evaporation determines the predictive skill for droughts, floods, and continental moisture recycling (Henderson-Sellers 2006).

\footnotetext{
Corresponding author: Francina Dominguez, francina@illinois. edu
}

However, in recent decades there has been a shift away from a bulk quantification of the water balance to a more nuanced understanding of the physical processes and pathways of water movement by tracking water through the terrestrial system using stable isotope tracers (McDonnell 2017). The isotopic composition changes in different stores and fluxes provide a recognizable signature of water transport in the surface-subsurface continuum (Gat 1996; McGuire and McDonnell 2006). These signatures have revealed that most of the runoff from natural watersheds and/or peak flow associated with rain storms is composed of displaced pre-event water (e.g., Sklash et al. 1976; Buttle 1994; Genereux and Hooper 1998; see review by Klaus and McDonnell 2013), and 
more recently that the water used for plant transpiration is different from the mobile water that supplies groundwater recharge (Brooks et al. 2010; Evaristo et al. 2015), suggesting a compartmentalization in time and space of the components of the water cycle.

These isotopic observations can be used to validate and improve LSMs' representation of the water cycle. This has been done by numerically incorporating an additional isotopic module in the LSM, and then directly comparing the modeled isotopic composition to observations (Aleinov and Schmidt 2006; Fischer 2006; Yoshimura et al. 2006; Sturm et al. 2010; Risi et al. 2016). The isotope-enabled LSM simulates the concentration changes of the hydrogen and oxygen isotopes $\left({ }^{1} \mathrm{H}^{2} \mathrm{H}^{16} \mathrm{O}\right.$ and $\mathrm{H}_{2}{ }^{18} \mathrm{O}$ ) through mixing, advection, diffusion, and related isotopic fractioning (e.g., Riley et al. 2002; Braud et al. 2005; Yoshimura et al. 2006; Fischer 2006; Aleinov and Schmidt 2006; Zhang et al. 2009; Haese et al. 2013; Risi et al. 2016). Isotopic signals reflect the accumulated transport and phase change features of the model (Yoshimura et al. 2006) and thus can probe the "correctness" of a model's parameterization (Henderson-Sellers 2006; McDonnell and Beven 2014). This approach is attractive because the observations and model results can be directly compared. A strength of this approach is that water isotopes from local measurements can yield relevant information to evaluate isotope-enabled LSMs at the large scale (Risi et al. 2016).

Therefore, multiple LSMs with isotope capability now exist, for example, Minimal Advanced Treatments of Surface Interaction and Runoff with stable water isotopes (iso-MATSIRO), Chameleon Surface Model with stable water isotopes (iCHASM), the Goddard Institute for Space Studies (GISS) isotopically enabled land-surface scheme (ILSS), ECHAM5-Jena Scheme for Biosphere-Atmosphere Coupling in Hamburg (JSBACH) with stable water isotopes (ECHAM5-JSBACH-wiso), and water isotopes in ORCHIDEE and CLM. However, the use of these isotope-enabled LSMs is hampered by their isotope-data-driven nature. For offline LSM simulations, spatially gridded isotope data of precipitation and ambient vapor is required in order to drive the isotopic compositions in the land surface (Kendall and Coplen 2001). For fully coupled regional atmosphereland simulations in which a climate model provides the atmospheric and isotopic forcing for the LSM, isotopic composition of water vapor is required as lateral boundary forcing for regional simulations. However, these isotopic observations are largely limited in time and space and are usually subject to discontinuities and discrepancies of scales between measurements and modeling, which makes it difficult to ingest in these isotopic-enabled LSMs (Twining et al. 2006; Fischer and
Sturm 2006; Risi et al. 2016), particularly when simulating historical events, when isotopic observations were not readily available. On the other hand, coupled global simulations (that do not require isotope data as lateral boundary conditions) rely entirely on the modeled representation of isotope physics and dynamics in the atmospheric-ocean and land system, thus increasing the uncertainties because they are not constrained by observations (Haese et al. 2013).

It is particularly difficult to numerically track water that originates from an individual precipitation event through the surface-subsurface system using isotopes (in observations or in models). As an example, to track an individual event using observations, the isotopic composition of soil water or streamflow $\delta_{\text {out }}(t)$ is estimated via the convolution integral of the isotope compositions of a series of precipitation events $\delta_{\text {in }}\left(t^{\prime}\right)$ and the transit time distribution (or system response function) $g\left(t-t^{\prime}\right)$ that reflects the transport in the subsurface. Tracking an individual event involves the deconvolution of the isotopic signature of each event, and this requires either an a priori assumption of a time-invariant transit time distribution (e.g., Stewart and McDonnell 1991; McGuire et al. 2002; McGuire and McDonnell 2010, hereafter MM2010) or high demands on isotope data to calibrate the time-variant transit time distribution (e.g., Klaus et al. 2015). Furthermore, some mixture of isotopically fractionated water in isotope-enabled LSMs may conceal or obscure the underlying movement of event water. Therefore, uncertainties associated with the assumptions on transit time distribution (Hrachowitz et al. 2009; Birkel et al. 2012; van der Velde et al. 2012) and isotopic fractionation parameterization when phase change occurs (e.g., Yoshimura et al. 2006; Risi et al. 2016) can hinder our ability to use isotopes for tracking water for individual events.

Here we present a new numerical tool to overcome past limitations and to track water through the terrestrial system. Using numerical tracers embedded in an LSM, we "tag" the water of a particular event (for example a storm, or a series of storms), and follow the water as it moves through the surface-subsurface until it ultimately leaves the system as evapotranspiration or runoff. Note that we are using numerical tracers to distinguish the event water from the rest of water in the model, which in the real world is achieved by the different water isotopic features from precipitation input. This tool tracks the event water rather than water isotopes; thus, it directly represents the water transit features without the complexity of isotopic physics.

The overarching goal of this paper is to understand hydrometeorological event dynamics as water moves through the surface-subsurface system with multiple 
characteristic spatiotemporal scales. The specific goals of this paper are as follows:

1) To present the water tracer tool within the Noah LSM with multiparameterization options (Noah-MP; Niu et al. 2011). Noah-MP has been widely used in climate and large-scale hydrological studies. It is the first LSM that has a numerical water tracer capability. We will refer to this tool as WT-Noah-MP.

2) To evaluate WT-Noah-MP using isotope observations from a small watershed in the northwestern United States.

3) To investigate the short and long-term impacts of an extreme precipitation event over a large region in the northwestern United States.

\section{Model description}

\section{a. Noah-MP}

Noah-MP (Niu et al. 2011) is an advanced LSM, based on the Noah model (Ek et al. 2003), and modified to include multiple physical processes. It has been used to study the large-scale water cycle in both standalone (e.g., Yang et al. 2011; Cai et al. 2014; Pilotto et al. 2015) and coupled simulations with the Weather Research and Forecast (WRF) Model (e.g., Barlage et al. 2015; Martinez et al. 2016) and its extended WRF-Hydro system (Gochis et al. 2013; Senatore et al. 2015). Similar to many other LSMs, Noah-MP has a single-level canopy model, a snow model, and a ground hydrology model (see water stores and fluxes in Fig. 1 and Table 1). On the other hand, Noah-MP is unique as a result of its flexibility to customize simulations because it provides multiple options to parameterize key processes (Barlage et al. 2015). We use the particular parameterization set shown in Table 2 to illustrate the water tracer implementation. Note that no lateral flow/routing is included in this particular model setting.

\section{b. Water tracer implementation in Noah-MP}

The water tracer module is a new set of equations that describe the dynamics of the partial storages and fluxes of the water tracers. The water tracers "tag" event precipitation and leave the system through evapotranspiration and runoff. Figure 1 shows how the tracers are conceptualized in each component of Noah-MP.

\section{1) Tracer INITIATION}

We initiate the water molecules from precipitation within a designated time window as water tracers. Before this time window, the tracer module is not activated, and the simulation is the same as the original Noah-MP. During the designated period, the precipitation is "tagged" and provides the input of tracers using (1). Therefore, the total tracer input equals the event precipitation designated by the time window. After this event, no further precipitation is being tagged but the existing tracers continue to be tracked until the end of simulation. The tracer input is calculated as

$$
F_{\mathrm{PP}}^{\prime}=F_{\mathrm{PP}} \times \mathrm{wt}_{\text {ratio }}, \quad \mathrm{wt}_{\text {ratio }}= \begin{cases}1, & \text { if timestep is within tagging period; } \\ 0, & \text { if timestep is before/after tagging period. }\end{cases}
$$

where $F_{\mathrm{PP}}^{\prime}$ is the tracer input from precipitation, $F_{\mathrm{PP}}$ is the total precipitation into the land surface, and $\mathrm{wt}_{\text {ratio }}$ is a ratio used to control tracer input.

\section{2) TRACERS IN SINGLE-LAYER CANOPY MODEL}

The canopy model characterizes the fraction covered by vegetation $f_{\text {veg }}$ in each model grid. The canopy can store water if intercepted by vegetation leafs and stems (Fig. 1, top), and the model allows canopy storages in both liquid water and ice phases. Forest canopies are capable of intercepting large quantities of precipitation, which account for $10 \%-50 \%$ of season-long or annual precipitation (Carlyle-Moses and Gash 2011).

The intercepted water from prior rain events is found to have important mixing effects with the current rainfall in generating throughfall (Allen et al. 2014). To account for the mixing between pre-event canopy storage and the water tracers, we assume a "well mixed" canopy model as in other isotope-enabled LSMs (Fig. 1; e.g., Fischer 2006; Yoshimura et al. 2006; Aleinov and Schmidt 2006). Over the grid area covered by vegetation $f_{\text {veg, }}$, the water tracers are immediately mixed with pre-event canopy storage with a mixing ratio of $R_{l, \text { canopy }}$ or $R_{i, \text { canopy }}$ :

$$
R_{l, \text { canopy }}=\frac{F_{l, \mathrm{PP}}^{\prime} \times f_{\mathrm{veg}} \times \delta t+W_{l, \text { canopy }}^{0} \times R_{l, \text { canopy }}^{0}}{W_{l, \text { canopy }}} \text { and } \quad R_{i, \text { canopy }}=\frac{F_{i, \mathrm{PP}}^{\prime} \times f_{\mathrm{veg}} \times \delta t+W_{i, \text { canopy }}^{0} \times R_{i, \text { canopy }}^{0}}{W_{i, \text { canopy }}}
$$




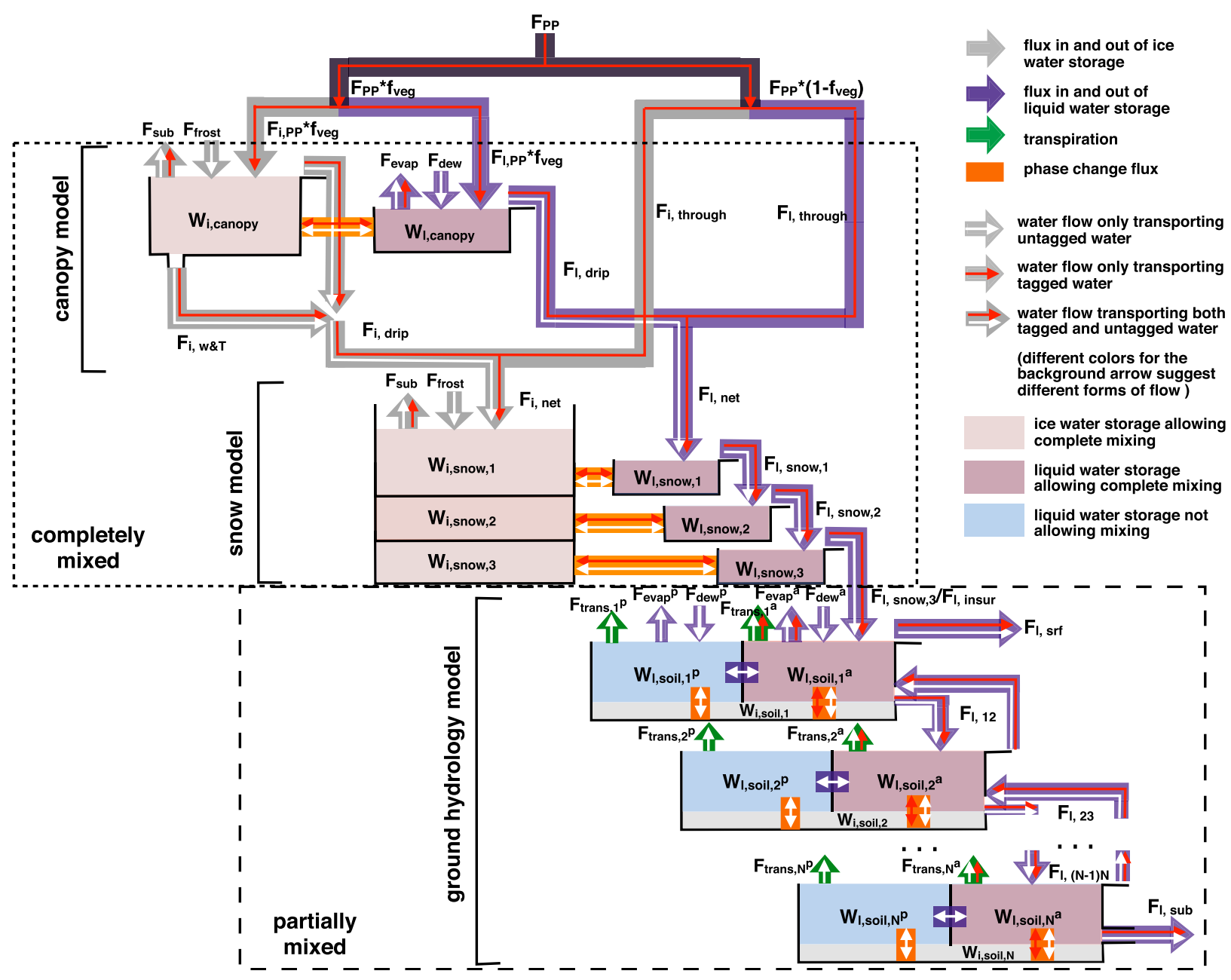

FIG. 1. Conceptualization of the processes in WT-Noah-MP. Fluxes and storages with bluish colors represent the form of liquid; fluxes and storage with the gray color are in the form of ice. See the legend and Table 3 for more information. Note that the soil moisture reservoir that stacks liquid on top of ice does not suggest the real placement but rather shows their shared holding capacity based on soil porosity.

where $F_{l, \mathrm{PP}}^{\prime}$ and $F_{i \mathrm{PP}}^{\prime}$ are tracer fluxes in the form of rain and snow, respectively; $\delta t$ is the interval of the model time step; $W_{l, \text { canopy }}^{0}$ and $W_{i, \text { canopy }}^{0}$ are total liquid water and ice storages from the previous time step; $R_{l, \text { canopy }}^{0}$ and $R_{i, \text { canopy }}^{0}$ are tracer mixing ratios for the liquid water and ice storages from the previous time step. Then, the tracer fluxes, such as evaporation, sublimation, drip-through, and phase changes, are all partitioned in proportion to $R_{l, \text { canopy }}$ or $R_{i, \text { canopy }}$ :

$$
\begin{cases}F_{l}^{\prime}=F_{l} \times R_{l, \text { canopy }}, & \text { if the flux is extracting water from the liquid water storage } \\ F_{i}^{\prime}=F_{i} \times R_{i, \text { canopy }}, & \text { if the flux is extracing water from the ice water storage }\end{cases}
$$

where $F_{l}^{\prime}$ and $F_{l}$ are the tracer and total fluxes from the liquid water storage $W_{l \text {,canopy }}$ through different processes while $F_{i}^{\prime}$ and $F_{i}$ are the tracer and total fluxes from the ice water storage $W_{i \text {,canopy. Note that we do }}$ not account for dew/frost, which is from the ambient water vapor, as a source for the water tracers to ensure that the only source for tracers is the tagged precipitation event.

\section{3) TRACERS IN THE SNOW MODEL}

Noah-MP uses a physically based snow model to simulate snowpack dynamics. The model has up to three layers (three individual stores) depending on the snowpack depth (Fig. 1, middle). The well-mixed assumption is assumed in each snow layer (e.g., Fischer 2006; Yoshimura et al. 2006; Aleinov and Schmidt 2006). 
TABLE 1. List of water stores and fluxes in Fig. 1.

\begin{tabular}{|c|c|c|}
\hline & Variable name & Variable description \\
\hline 1 & $F_{\mathrm{PP}}$ & Precipitation flux \\
\hline 2 & $F_{\mathrm{PP}} \times f_{\text {veg }}$ & Precipitation flux over the fraction with vegetation coverage $f_{\text {veg }}$ \\
\hline 3 & $F_{\mathrm{PP}} \times\left(1-f_{\mathrm{veg}}\right)$ & Precipitation flux over the fraction without vegetation coverage \\
\hline 4 & $F_{i, \mathrm{PP}} \times f_{\mathrm{veg}}$ & Snowfall flux over the fraction with vegetation coverage $f_{\text {veg }}$ \\
\hline 5 & $F_{l, \mathrm{PP}} \times f_{\mathrm{veg}}$ & Rainfall flux over the fraction with vegetation coverage $f_{\text {veg }}$ \\
\hline 6 & $F_{\text {sub }}$ & Sublimation flux \\
\hline 7 & $F_{\text {frost }}$ & Frost flux \\
\hline 8 & $F_{\text {evap }}$ & Evaporation flux \\
\hline 9 & $F_{\text {dew }}$ & Dew flux \\
\hline 10 & $F_{i, \text { drip }}$ & Drip rate of canopy ice \\
\hline 11 & $F_{l, \text { drip }}$ & Drip rate of canopy liquid water \\
\hline 12 & $F_{i, \mathrm{w} \& \mathrm{~T}}$ & Extra drip rate of canopy ice due to wind and temperature \\
\hline 13 & $F_{i, \text { through }}$ & Throughfall rate of snowfall \\
\hline 14 & $F_{l, \text { through }}$ & Throughfall rate of rainfall \\
\hline 15 & $F_{i, \text { net }}$ & Net snowfall rate due to drip-through and throughfall \\
\hline 16 & $F_{l, \text { net }}$ & Net rainfall rate due to drip-through and throughfall \\
\hline 17 & $F_{l, \text { snow }, n}$ & downward liquid flow from snow layer $n$ \\
\hline 18 & $F_{l, \text { insur }}$ & Input liquid water flux to soil surface \\
\hline 19 & $F_{l, \mathrm{srf}}$ & Surface runoff rate \\
\hline 20 & $F_{l, n(n+1)}$ & Liquid water fluxes between soil layer $n$ and layer $n+1$ \\
\hline 21 & $F_{l, \text { sub }}$ & Subsurface runoff rate \\
\hline 22 & $F_{\text {trans }, n}$ & Transpiration flux from soil layer $n$ \\
\hline 23 & $W_{i, \text { canopy }}$ & Canopy storage of ice \\
\hline 24 & $W_{l, \text { canopy }}$ & Canopy storage of liquid water \\
\hline 25 & $W_{i, \text { snow }, n}$ & Ice storage in snow layer $n$ \\
\hline 26 & $W_{l, \text { snow }, n}$ & Liquid water storage in snow layer $n$ \\
\hline 27 & $W_{i, \text { soil }, n}$ & Ice storage in soil layer $n$ \\
\hline 28 & $W_{l, \text { soil }, n}$ & Liquid water storage in soil layer $n$ \\
\hline
\end{tabular}

The tracer input as rainfall/snow increases the storage of the topmost snow layer, following the original NoahMP. The fluxes contributing to sublimation, phase change, and snow layer dividing/combining are derived using similar equations to (2) and (3). In particular, when the downward percolation occurs $F_{l, \text { snow }, n}$ due to rain on snow or snowmelt, the tracer flux $F_{l, \text { snow }, n}^{\prime}$ is calculated using (4):

$$
\begin{aligned}
R_{l, \text { snow }, n} & =\frac{F_{l, \text { snow }, n-1} \times R_{l \text {,snow }, n-1} \times \delta t+W_{l, \text { snow }, n}^{0} \times R_{l, \text { snow }, n}^{0}}{F_{l, \text { snow }, n-1} \times \delta t+W_{l, \text { snow }, n}^{0}} \\
F_{l, \text { snow }, n}^{\prime} & =F_{l, \text { snow }, n} \times R_{l, \text { snow }, n},
\end{aligned}
$$

where $F_{l, \text { snow }, n-1}$ and $R_{l, \text { snow }, n-1}$ are the total liquid flow and tracer mixing ratio from the layer above, $W_{l, \text { snow }, n}^{0}$

TABLE 2. Option set for physical processes used in Noah-MP.

\begin{tabular}{rll}
\hline \multicolumn{2}{c}{ Physical processes } \\
\hline 1 & Dynamic vegetation & Options \\
2 & Canopy stomatal resistance & 4 (use table LAI; use maximum vegetation fraction) \\
3 & Soil moisture factor for stomatal resistance & 1 (Ball-Berry) \\
4 & Runoff and groundwater & 1 (Noah) \\
5 & Surface layer drag coefficient & 1 (free drainage) \\
6 & Supercooled liquid water & 1 (no iteration) \\
7 & Frozen soil permeability & 1 (linear effects) \\
8 & Radiation transfer & 3 (two-stream approximation applied to vegetated fraction) \\
9 & Ground snow surface albedo & 2 (CLASS) \\
10 & Partitioning precipitation into rainfall and snowfall & 1 (Jordan) \\
11 & Lower boundary condition of soil temperature & 2 (original Noah) \\
12 & Snow/soil temperature time scheme & 1 (semi implicit) \\
13 & Surface resistance to evaporation/sublimation & 1 (Sakaguchi and Zeng 2009) \\
\hline
\end{tabular}


and $R_{l, \text { snow }, n}^{0}$ are the total liquid storage and tracer mixing ratio of layer $n$ at the prior time step, and $R_{l, \text { snow }, n}$ is the mixing ratio of tracers in liquid storage of layer $n$. Therefore, we assume that the meltwater flux is spatially uniform and homogeneously mixed as it percolates through the snowpack (Judy et al. 1970; Stichler 1987; Raben and Theakstone 1998). However, we are not accounting for meltwater percolation down preferential pathways or discrete "fingers" (e.g., Gerdel 1954; Marsh and Woo 1984); accounting for this process requires a more sophisticated snow model to represent the heterogeneity of the melting process (e.g., Feng et al. 2002; Lee et al. 2010).

\section{4) TRACERS IN THE GROUND HYDROLOGIC MODEL}

In this study, we use a simple combination of an infiltration-excess-based surface runoff scheme and a gravitational free-drainage subsurface runoff scheme as used in the original Noah LSM (Schaake et al. 1996). Note that Noah-MP provides more sophisticated runoff and groundwater schemes to account for soil-groundwater interactions; the tracers could be extended to these schemes in the future. At the soil surface, the total water input $F_{l, \text { insur }}$ can generate infiltration-excess surface runoff $F_{l, \text { srf }}$, which is partitioned into the tracer contribution $F_{l, \mathrm{srf}}^{\prime}$ :

$$
\begin{aligned}
R_{l, \text { insur }} & =\frac{F_{l, \text { insur }}^{\prime}}{F_{l, \text { insur }}} \\
F_{l, \text { srf }}^{\prime} & =F_{l, \text { srf }} \times R_{l, \text { insur }},
\end{aligned}
$$

where $R_{l, \text { insur }}$ is the mixing ratio of tracer input at the soil surface to total input, and $F_{l, \text { insur }}^{\prime}$ and $F_{l \text {,insur }}$ are the tracer and total water input at the soil surface, respectively. The rest is infiltrated into the soil column. The critical issue is the partitioning of subsurface fluxes into tracer fluxes within the soil column.
In Noah-MP, the liquid water in each soil layer is updated using Richards' equation:

$$
\frac{\partial \theta}{\partial t}=\frac{\partial}{\partial z}\left[D(\theta) \frac{\partial \theta}{\partial z}\right]+\frac{\partial K(\theta)}{\partial z}
$$

where $\theta$ is the soil water content that can be converted to water storage $W_{l, \text { soil, }, n}$ multiplied by the soil thickness $\delta z$, $K(\theta)$ is the hydraulic conductivity, and $D(\theta)$ is the soil water diffusivity. The term $K(\theta)[D(\theta)]$ is parameterized as a function of $\theta$ and saturated hydraulic conductivity $K_{\text {sat }}$ (saturated diffusivity $D_{\text {sat }}$ ). In Noah-MP, $K_{\text {sat }}$ and $D_{\text {sat }}$ are assigned according to soil type, neglecting the vertical variations. In our simulations, we use observed profiles of these parameters from field experiments for the small watershed in the northwestern United States (section 4a) to account for the compaction with soil depth. However, we use the assigned parameters without vertical variation for the regional-scale simulation (section 4b) as in the default Noah-MP due to the lack of observations. For all soil layers, the equations in the form of (6) are solved together through a tridiagonal matrix using a time-implicit scheme (Niu et al. 2011).

Tracing water through the soil column is perhaps the most problematic aspect of the tracer model. The difficulty in implementing tracers using Richards' equation is that (6) is not valid for tracer soil water (we cannot replace $\theta$ with $\theta^{\prime}$ ). The reason is that the tracer water moves in proportion to the gradient in total moisture content, not the gradient in tracer moisture content. For this reason, we first calculate the total flux (the final form of which was not explicitly calculated in the original Noah-MP due to the time-implicit scheme), then partition the flux by multiplying by the mixing ratio tracer soil water to total soil water. In the discussion that follows, we are assuming a well-mixed reservoir within each layer (in section $2 \mathrm{c}$ we describe how to account for incomplete mixing). The water budget equations for total and tracer soil moisture are described in (7) and (8):

$$
\begin{cases}\frac{\theta_{1}-\theta_{1}^{0}}{\delta t}=\frac{\left(F_{l, \text { insur }}-F_{l, \mathrm{srf}}\right)-F_{l, 12}-F_{\text {evap }}-F_{\text {trans }, 1}}{\delta z_{1}}, & \text { for soil layer } 1 ; \\ \frac{\theta_{n}-\theta_{n}^{0}}{\delta t}=\frac{F_{l,(n-1) n}-F_{1, n(n+1)}-F_{\text {trans }, n},}{\delta z_{n}} & \text { for soil layer } 1<n<N ; \quad \text { and } \\ \frac{\theta_{N}-\theta_{N}^{0}}{\delta t}=\frac{F_{l,(N-1) N}-F_{l, \mathrm{sub}}-F_{\text {trans }, N}}{\delta z_{N}}, & \text { for soil layer } N\end{cases}
$$




$$
\left\{\begin{aligned}
\frac{R_{1} \theta_{1}-R_{1}^{0} \theta_{1}^{0}}{\delta t}= & \frac{\left(F_{l, \text { insur }}^{\prime}-F_{l, \text { srf }}^{\prime}\right)-R_{1} \max \left(F_{l, 12} 0\right)-R_{2} \min \left(F_{l, 12}, 0\right)}{\delta z_{1}} \\
& +\frac{-R F_{\text {evap }}-R_{1} F_{\text {trans }, 1},}{\partial z_{1}} \text { for soil layer } 1 ; \\
\frac{R_{n} \theta_{n}-R_{n}^{0} \theta_{n}^{0}}{\delta t}= & \frac{R_{n-1} \max \left(F_{l,(n-1) n}, 0\right)+R_{n} \min \left(F_{l,(n-1) n}, 0\right)-R_{n} \max \left(F_{l, n(n+1)}, 0\right)}{\partial z_{n}} \\
& +\frac{-R_{n} \min \left(F_{l, n(n+1)}, 0\right)-R_{n} F_{\text {trans }, n}}{\partial z_{n}}, \text { for soil layer } 1<n<N ; \\
\frac{R_{N} \theta_{N}-R_{N}^{0} \theta_{N}^{0}}{\delta t}= & \frac{R_{N-1} \max \left(F_{l,(N-1) N}, 0\right)+R_{N} \min \left(F_{l,(N-1) N}, 0\right)}{\partial z_{n}} \\
& +\frac{-R_{N} F_{l, \text { sub }}-R_{N} F_{\text {trans }, N}}{\partial z_{N}}, \text { for the bottom soil layer } N,
\end{aligned}\right.
$$

where $\theta_{n}$ and $\theta_{n}^{0}$ are the total soil water contents of layer $n$ at the current time step and the prior time step, $F_{l,(n-1) n}$ is the total flux between layer $n-1$ and $n$ (taking downward direction as positive), and $R_{n}$ and $R_{n}^{0}$ are the mixing ratios of tracer soil water to total soil water in layer $n$ at the current and the prior time steps, respectively. To solve for $R_{1}-R_{N}$, we first calculate the interlayer fluxes $F_{l,(n-1) n}$ using (7), and subsequently calculate the only unknowns $R_{1}-R_{N}$ in (8). Finally, the tracer fluxes and storages of each layer can be obtained assuming proportional extractions using $R_{1}-R_{N}$.

\section{c. Partial mixing in soil}

The assumption of complete mixing of tracers with existing soil water is likely inadequate (Godsey et al. 2009; Rouxel et al. 2011; Hrachowitz et al. 2016). The tracer response can be very different from the bulk-flux response (e.g., derived from Richards' equation or streamflow from an outlet) that largely manifests the effect of hydraulic gradients (i.e., the difference between velocity and celerity) (see more details in McDonnell and Beven 2014; Hrachowitz et al. 2016). Water can bypass the soil matrix through macropores and reach specific depths faster than water moving through soil micropores (Ranken 1974; McDonnell 1990; Leaney et al. 1993; Kendall and McDonnell 1998; Buttle and McDonald 2002). To account for the dual response time scales, studies have conceptualized the flow through preferential pathways and the soil matrix by separating the total storage into "active/mobile" and "passive/ immobile" storage compartments in modeling (e.g., Fenicia et al. 2010; Hrachowitz et al. 2013). Under relatively dry conditions, a high portion of incoming precipitation (water tracers in our case) can be transiently stored in the porous flow media and interact with resident water of varying ages; as the system wets up, more water is likely to bypass the matrix through preferential flowpaths due to higher hydrologic connectivity (Hrachowitz et al. 2013,2016). This separation of active and passive storages is broadly consistent with the ecohydrological separation found by isotopic studies, suggesting different storages that supply plant transpiration (passive/immobile) and groundwater recharge and streamflow (active/mobile) (Brooks et al. 2010; Evaristo et al. 2015).

However, the parameterization of such a dynamical partial mixing usually introduces extra parameters that require calibration (e.g., McGuire et al. 2007; Hrachowitz et al. 2013; Evaristo et al. 2015). To represent the effect of partial mixing, yet keep the simplicity of the model application, we simplify the above process by 1) separating the total storage in each soil layer into half "mobile" and half "immobile" components (see the different stores of water in Fig. 1),2) assuming the input tracer flux only passes the mobile storage (Fig. 1, bottom), and 3) updating the two storages-mobile and immobile-with the total storage of each layer (half mobile and half immobile) while neglecting tracer exchange between the two half storages (i.e., updating of the immobile half storage is achieved through nontracer water exchanges). Therefore, we are assuming that the incoming tracer flux only mixes with half of the storage that is active/mobile, while the other half can be conceptualized as the water that is retained in the soil matrix and is assumed to be passive/immobile. These simplifications are more applicable for wet conditions, which 
(a) Total soil water

(b) Tracer soil water mixed in each soil layer (c) Tracer soil water mixed in each $1 / 2$ layer (d) Tracer soil water mixed in each $1 / 4$ layer

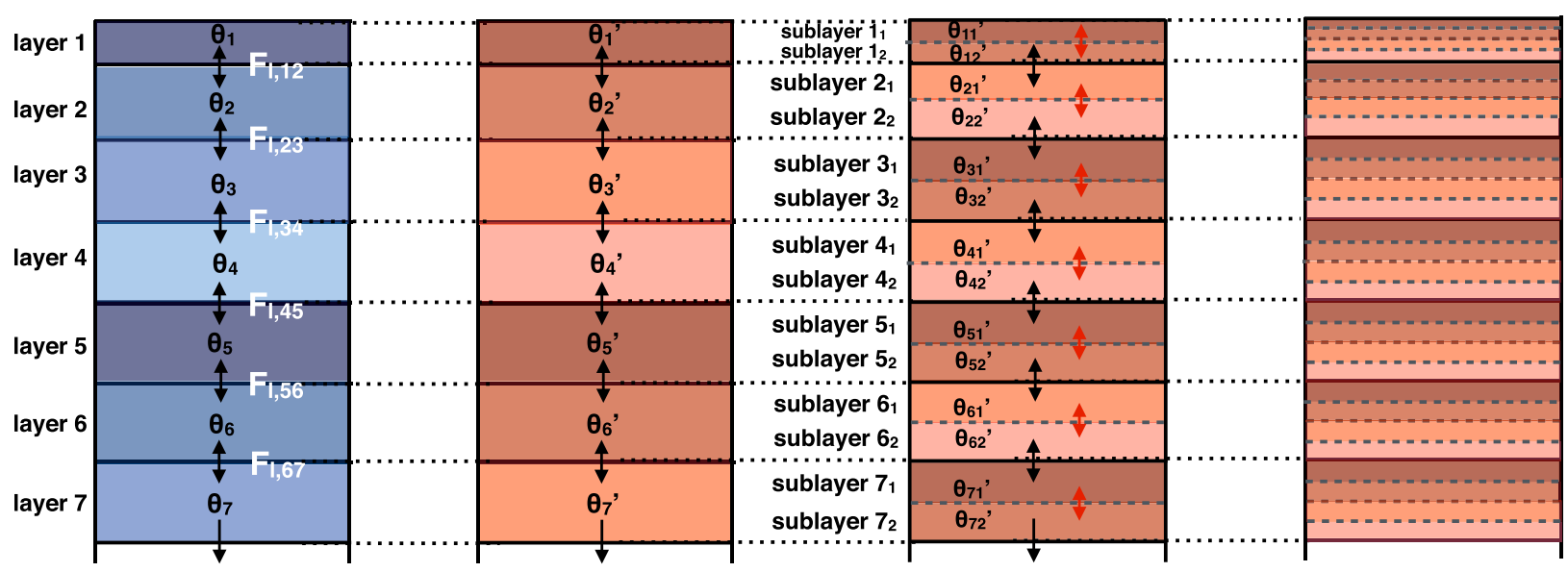

FIG. 2. Schematics of (a) the soil layer configuration in Noah-MP, (b) the mixing of tracers in each soil layer as Noah-MP, (c) the mixing of tracers in each $1 / 2$ layer, and (d) the mixing of tracers in each $1 / 4$ layer.

are characterized by a faster transfer of younger water bypassing the soil matrix. While simplistic, this allows us to investigate the tracer responses to different mixing assumptions without introducing additional parameters. In future applications, the fraction of the storage that is mobile or immobile can be changed according to the research question and specific conditions of the region.

In addition to partitioning into mobile and immobile, we also increased the number of soil sublayers in the tracer parameterization. The original soil layer thickness (up to $1 \mathrm{~m}$ in the default Noah-MP and up to $0.4 \mathrm{~m}$ in our case) may be too thick to resolve the vertical profile of tracers, especially for relatively short model time steps (from $30 \mathrm{~min}$ to $1 \mathrm{~h}$ in this study). Such a homogeneous mixing will likely result in an earlier arrival of the tracer to a certain depth but with a more dispersed transit time distribution than in observations (see results in section 3). To account for the vertical heterogeneity of tracer movement, we increase the number of layers in the soil when dealing with the tracers (not the bulk flow). We assume mixing within $1 / 2$ and $1 / 4$ depth of each original soil layer (from Fig. $2 b$ to Figs. $2 c, d$ ). To obtain the tracer flux and storage in each sublayer, we use the same equations as (8) to solve for the mixing ratios in each sublayer. Using sublayers, the transpiration flux $F_{\text {trans }, n}$ becomes $1 / 2$ or $1 / 4$ of $F_{\text {trans }, n}$ in each sublayer, and the interlayer fluxes become those between sublayers (red arrows in Fig. 2c). These sublayer fluxes are obtained from linear interpolation of the bounded whole-layer fluxes (e.g., $F_{l, 12}$ and $F_{l, 23}$ in Fig. 2a). In this way, we are able to preserve the flux gradient $(\partial$ Flux $/ \partial z)$ of the thicker original layer throughout the sublayers and maintain the vertical profile of soil moisture as invariant.
In summary, we account for the horizontal and vertical heterogeneity of tracer transport in the subsurface by allowing partial mixing in each soil layer by 1) accounting for mobile and immobile storage, where the tracers only interact with the mobile storage, and 2) subdividing the original model layers into additional sublayers when quantifying tracer movement. We test these different assumptions and their impact on the tracer flow and transport over a 10-ha watershed in western Oregon (WS10). Like the "virtual experiment" approach introduced by Weiler and McDonnell (2004), over WS10 we collectively combine the numerical experiments using WT-Noah-MP using different mixing assumptions and the field experiments for the purposes of exploring first-order controls on the transit time distribution of a controlled watershed. In addition, we demonstrate the use of WT-Noah-MP over a large region in the U.S. Pacific Northwest (western Washington) as an exploratory tool to quantify short- and long-term impacts of an extreme precipitation event, with these partial-mixing assumptions incorporated as a measure of uncertainty.

\section{Study sites and model configurations}

a. WS10 watershed

WS10 (10.2 ha) is located in the H. J. Andrews Experiment Forest, as part of a larger research effort of the Long-Term Ecological Research (LTER) program in the west-central Cascade Mountains of Oregon $\left(44.2^{\circ} \mathrm{N}\right.$, $122.25^{\circ} \mathrm{W}$; McGuire et al. 2007). WS10 (Fig. 3a) is equipped with a comprehensive network of instrumentation and has been intensively studied for forest ecological 
(a)

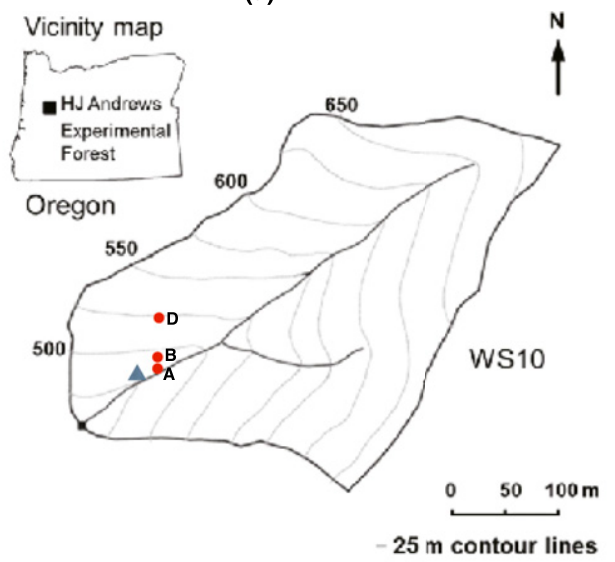

(c)

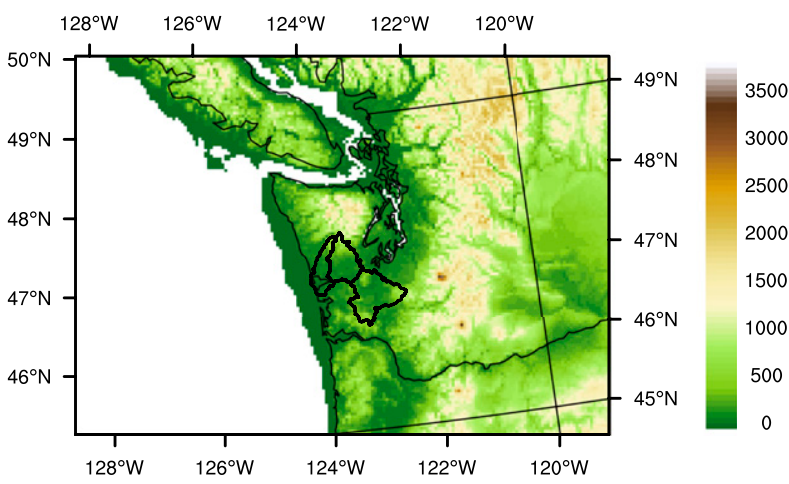

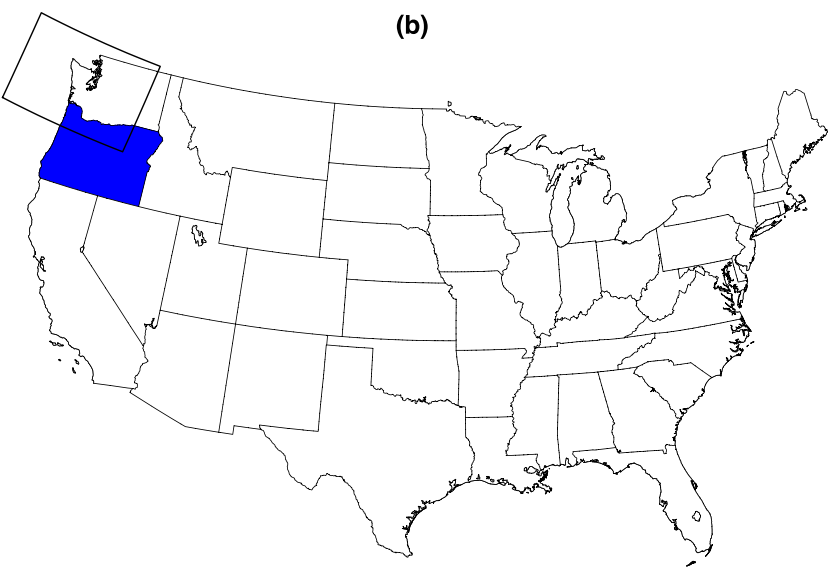

(d)

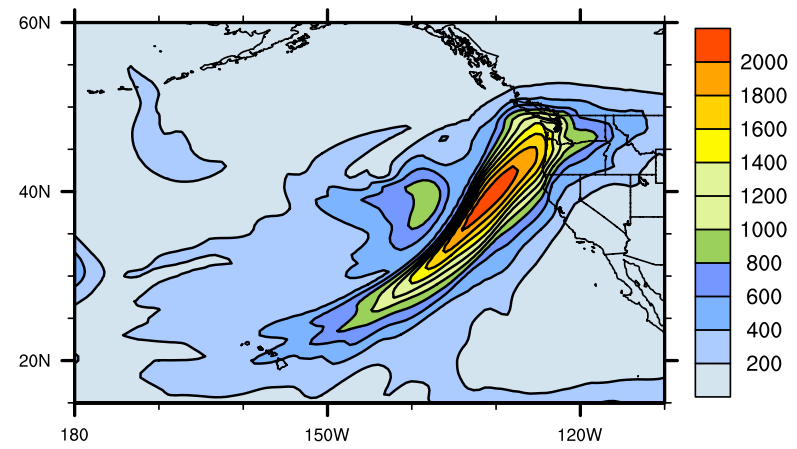

FIG. 3. (a) Map of WS10 of the H. J. Andrews Experimental Forest and the location within Oregon (from Klaus et al. 2015). The blue triangle represents the location of the soil moisture probes. The red dots represent the locations of lysimeters that collect isotope measurements. (b) Map of the United States with Oregon highlighted in blue, within which WS10 is located, and the domain for western Washington highlighted with the black box. (c) Topographic features (m) of the domain of western Washington with the Chehalis River basin delineated in black. (d) Well-defined AR signature at 1200 UTC 3 Dec 2007 shown by the narrow structure of vertically integrated vapor transport $\left(\mathrm{kg} \mathrm{m}^{-1} \mathrm{~s}^{-1}\right)$, which has significantly impacted the Chehalis River basin.

and hydrological research (e.g., Jones 2000; MM2010; Klaus et al. 2015).

The vegetation type is a naturally regenerated secondgrowth Douglas fir forest after a 1975 clear-cut harvest. The catchment is steep, with slopes ranging from $30^{\circ}$ to over $45^{\circ}$ and elevations from 473 to $680 \mathrm{~m}$. It contains residual and colluvial clay loam soils with an average soil depth of $1.3 \mathrm{~m}$. Surface soils are well aggregated, but lower depths $(70-100 \mathrm{~cm})$ have a more massive blocky structure with less aggregation. Beneath is partially weathered bedrock with poor permeability in thicknesses from 1 to $7 \mathrm{~m}$ ( $\sim 3.7 \mathrm{~m}$ on average). Annual precipitation is $2200 \mathrm{~mm}$ (1979-2008), about $80 \%$ of which falls between October and April. Consequently, the catchment gradually wets up from October to December and maintains the wet conditions until late spring. Runoff generation in the catchment shows clear thresholds, hysteresis, and event transit times varying with antecedent conditions. More details about WS10 can be found in McGuire et al. (2007), MM2010, Klaus et al. (2015), and Hale and McDonnell (2016).

In a field experiment carried out in the 2002/03 winter rainy season, oxygen-18 $\left({ }^{18} \mathrm{O}\right)$ samples were collected weekly for bulk precipitation and at time intervals between daily and weekly for soil water from the lysimeters (Fig. 3a). MM2010 used the data collected and a lumped parameter convolution model (Stewart and McDonnell 1991; McGuire et al. 2002, 2005) to examine the transit time of soil water along depth (red dots in Fig. 3a). To compare isotope observations to the numerical tracer model, we use a measure of "transit time" derived from the numerical tracers.

\section{b. Western Washington State}

Located to the north of WS10, the regional simulation we conduct covers the western part of Washington state 
(Figs. 3b,c). This mountainous domain covers the Cascade Mountains on the east and the Olympic Mountains close to the coastline. Surrounded by these mountains, the Chehalis River basin (delineated by black in Fig. 3c) is flood-prone for storms over the mountains. Similar to WS10 in Oregon, western Washington is also frequently affected by winter storms. In particular, most of its winter precipitation $(>60 \%)$ can be attributed to atmospheric river (AR) events (Rutz et al. 2014). ARs are structures of intense water vapor transport in the atmosphere, most of which is converted into precipitation over the U.S. West Coast (see more details in Zhu and Newell 1998; Neiman et al. 2008; Ralph and Dettinger 2012). During 1-3 December 2007, an exceptionally intense AR event with well-defined filamentary structure of vapor transport (Fig. 3d) severely impacted the Chehalis basin (see more details in NWS 2008).

\section{c. Noah-MP configurations and forcing data}

\section{1) WATERSHED-SCALE SIMULATION, WS10}

Noah-MP is configured with seven soil layers $(0.1,0.3$, $0.3,0.3,0.3,0.3,0.4 \mathrm{~m}$ in thickness for each layer from top to bottom) with a total soil depth of $2.0 \mathrm{~m}$. The soil type is prescribed as clay loam, and the vegetation type as evergreen needleleaf forest. Noah-MP is run offline and uses the North American Land Data Assimilation System (NLDAS; Mitchell 2004) data $\left(1 / 8^{\circ}\right.$ grid and hourly resolution) as forcing data, which includes precipitation, downward shortwave and longwave radiation, near-surface air temperature, wind and humidity, and surface pressure. We run the single-column simulation using data from the grid point in NLDAS that is closest to the location of WS10 $\left(44.25^{\circ} \mathrm{N}, 122.25^{\circ} \mathrm{W}\right)$, with initial soil conditions provided by Noah LSM simulations from NLDAS. The simulation period is from 1 January 1999 to 31 December 2004 with a model time step of $30 \mathrm{~min}$, and thus it encompasses the time period of the field tracer experiment in MM2010. We use the parameterizations shown in Table 2.

In contrast with the default version of Noah-MP, we also incorporate the vertical variations in soil properties according to observed profiles from field observation. McGuire et al. (2007) fitted exponential functions to observations to represent vertical profiles for saturated hydraulic conductivity $K_{\text {sat }}$ and drainable porosity $n_{d}$ in the form of

$$
\begin{aligned}
K_{\mathrm{sat}}(z) & =k_{0} \exp (-z / f) \quad \text { and } \\
n_{d} & =n_{0} \exp (-z / d),
\end{aligned}
$$

where $k_{0}=8.7\left(\mathrm{~m} \mathrm{~h}^{-1}\right), f=0.56, n_{0}=0.26$, and $d=1.12$. We use these two functions to replace the two components for computing hydraulic conductivity $K(z)$ in Noah-MP as (11) by (12):

$$
\begin{aligned}
& K(z)=K_{\text {sat }}\left[\frac{\theta(z)}{\theta_{\max }}\right]^{2 b+3} \text { and } \\
& K(z)=K_{\text {sat }}(z)\left[\frac{\theta(z)-\theta_{r}(z)}{\theta_{\max }-\theta_{r}(z)}\right]^{2 b+3},
\end{aligned}
$$

where $\theta_{\max }$ is the soil porosity and $\theta_{r}(z)$ is assumed to be soil moisture retained after draining with $100 \mathrm{~cm}$ of tension $\left[\theta_{r}(z)=\theta_{\max }-n_{d}(z)\right]$. By doing this, we improve the representation of both $K_{\text {sat }}$ and effective saturation $\left\{\left[\theta(z)-\theta_{r}(z)\right] /\left[\theta_{\max }-\theta_{r}(z)\right]\right\}$. The same replacement for effective saturation is also used to compute hydraulic diffusivity $D(z)$. The sensitivity of the $b$ parameter in (12) is tested around its mean within a standard deviation (8.52 \pm 3.44; data from Clapp and Hornberger 1978).

\section{2) RegiOnAL-SCALE SiMULATION, WESTERN WASHINGTON}

We perform the simulation over the spatial domain shown in Fig. 3c. It has 3-km grid spacing with prescribed soil, vegetation, and topographic parameters derived from 30-arc-s-resolution geographical dataset (http:// www2.mmm.ucar.edu/wrf/users/download/get_sources_ wps_geog.html). We use the same soil layer configuration as in WS10. The simulation is forced by the Global Land Data Assimilation System (GLDAS; $14^{\circ}$ spatial resolution and hourly temporal resolution; Rodell et al. 2004) and initialized by state variables from the Noah LSM simulation in GLDAS. Note that NLDAS is not used because artificial contrasts of precipitation forcing are found at the U.S.-Canada border, which is probably due to deficiencies in the data assimilation algorithm (not shown). The same set of parameterizations shown in Table 2 is used. We run the simulation for the period from 1 July 2007 to 30 June 2008, with a model time-step interval of $1 \mathrm{~h}$. Note that no observation-based vertical profiles of soil properties are incorporated in this regional-scale simulation.

\section{d. Experiments using WT-Noah-MP}

\section{MIXING EXPERIMENTS}

To test the different assumptions of subsurface mixing, we implement four types of numerical experiments using WT-Noah-MP:

1) CM: complete mixing scenario in each soil layer;

2) PM: partial mixing scenario with half active/mobile storage;

3) $\mathrm{CM}-1 / 2$ and CM-1/4: complete mixing scenario with mixing in every $1 / 2$ and $1 / 4$ thickness of soil layer; 
TABLE 3. The tagged time periods for 11 precipitation events.

\begin{tabular}{rll}
\hline & \multicolumn{1}{c}{ Start of tagging } & \multicolumn{1}{c}{ End of tagging } \\
\hline 1 & 0000 UTC 16 Nov 2002 & 0000 UTC 19 Nov 2002 \\
2 & 0000 UTC 9 Dec 2002 & 0000 UTC 12 Dec 2002 \\
3 & 0000 UTC 12 Dec 2002 & 0000 UTC 15 Dec 2002 \\
4 & 0000 UTC 20 Dec 2002 & 0000 UTC 23 Dec 2002 \\
5 & 0000 UTC 29 Dec 2002 & 0000 UTC 1 Jan 2003 \\
6 & 0000 UTC 2 Jan 2003 & 0000 UTC 5 Jan 2003 \\
7 & 0000 UTC 11 Jan 2003 & 0000 UTC 14 Jan 2003 \\
8 & 0000 UTC 21 Jan 2003 & 0000 UTC 24 Jan 2003 \\
9 & 0000 UTC 24 Jan 2003 & 0000 UTC 27 Jan 2003 \\
10 & 0000 UTC 29 Jan 2003 & 0000 UTC 1 Feb 2003 \\
11 & 0000 UTC 15 Feb 2003 & 0000 UTC 18 Feb 2003 \\
\hline
\end{tabular}

4) $\mathrm{PM}-1 / 2$ and PM-1/4: partially mixed scenario in every $1 / 2$ and $1 / 4$ thickness of soil layer.

For WS10, we use the WT-Noah-MP tool to tag 11 individual precipitation events (storms 5-15 in MM2010). These events are chosen because they occurred after the wet-up phase, and thus we could focus on wet conditions. The time windows used to tag each storm are shown in Table 3 with a 3-day duration of each event. In total, we run 11 simulations with the same configuration but with different storm events tagged using (1).

For the spatial simulation of western Washington, we tag the extreme AR event in December 2007. We specify the precipitation falling from 0000 UTC 1 December to 0000 UTC 10 December 2007 as tagged water.

\section{Results and discussion}

\section{a. Watershed-scale simulation of WS10 (Oregon)}

In this section, we apply the WT-Noah-MP model to WS10 to explore the dominant process controls on water transit time. Specifically, we conduct a series of "virtual experiments," characterized by different hypotheses of subsurface mixing. We compare our numerical results to the results from observational field tracer experiments with the goal of evaluating the WT-Noah-MP tool. Figure 4a shows the measured soil moisture at a location $15 \mathrm{~m}$ from the slope base (blue triangle in Fig. 3a) and Fig. 5a shows the best-fit transit time distributions using observed $\delta^{18} \mathrm{O}$.

\section{1) SOIL MOISTURE SIMULATION}

Before evaluating the tracer dynamics, we evaluate the simulation of the total soil moisture from Noah-MP. Figures $4 \mathrm{~b}$ and $4 \mathrm{c}$ show the soil moisture at three different levels $(\sim 30,70$, and $100 \mathrm{~cm})$ from 1 September 2002 to 1 April 2003 [with $b=5.08$ in (12)]. Consistent with observations from MM2010 (Fig. 4a), simulated soil moisture (Fig. 4b) shows a wetting-up period on approximately 10 November 2002, marking the beginning of the winter rainy season. In addition, the observed delay in wetting with depth is also represented in NoahMP. After the wetting-up period (after 10 December 2002), the transient fluctuations in soil moisture as responses to precipitation events in Noah-MP are very similar to those from observations, and the simulated soil moisture captures the increasing trend with depth as observed. However, the Noah-MP simulations underestimate the vertical gradients in soil moisture with means increasing from $24.6 \%$ at $30 \mathrm{~cm}$ to $33.2 \%$ at $70 \mathrm{~cm}$ to $43.5 \%$ at $100 \mathrm{~cm}$ (averaged over the period shown in Fig. $4 \mathrm{a}$ ), while the simulated means are $35.1 \%$ at $25 \mathrm{~cm}$, $37.3 \%$ at $70 \mathrm{~cm}$, and $38.3 \%$ at $100 \mathrm{~cm}$ (Fig. $4 \mathrm{~b}$ ).

The simulation of vertical gradients in soil moisture improves with decreasing $b$ parameter values in (12).

(a) Total soil moisture observed at WS10 from McGuire and McDonnell (2010)

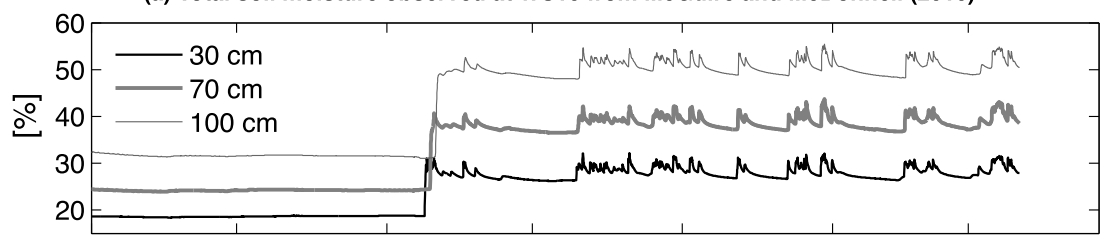

(b) Total soil moisture simulated by Noah-MP $(b=5.13)$

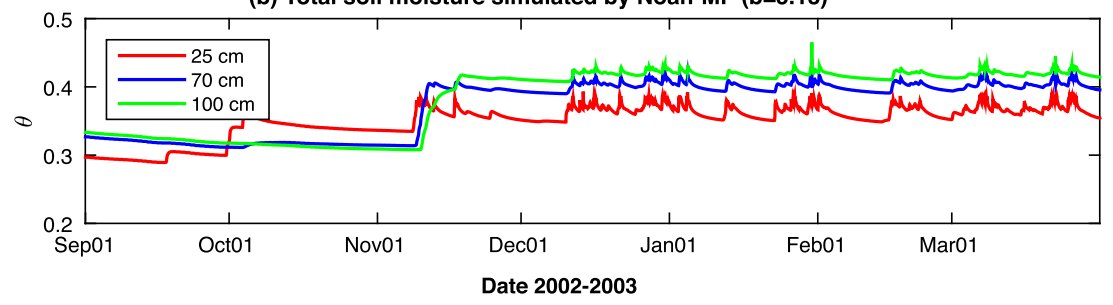

FIG. 4. Time series of the volumetric water content $\theta$ (a) at the location represented by the blue triangle in Fig. 4 (adapted from MM2010) and (b) from the single-column simulation from Noah-MP. 
(a)
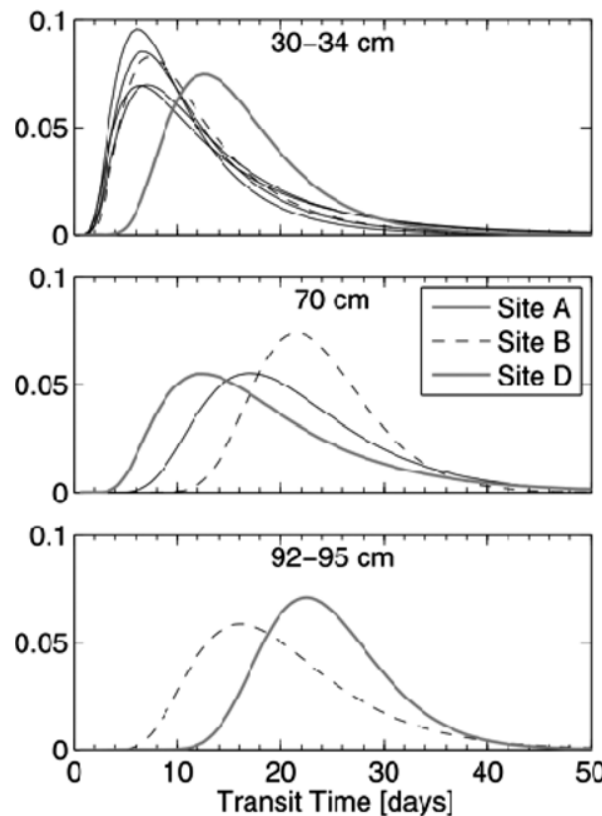

(b)
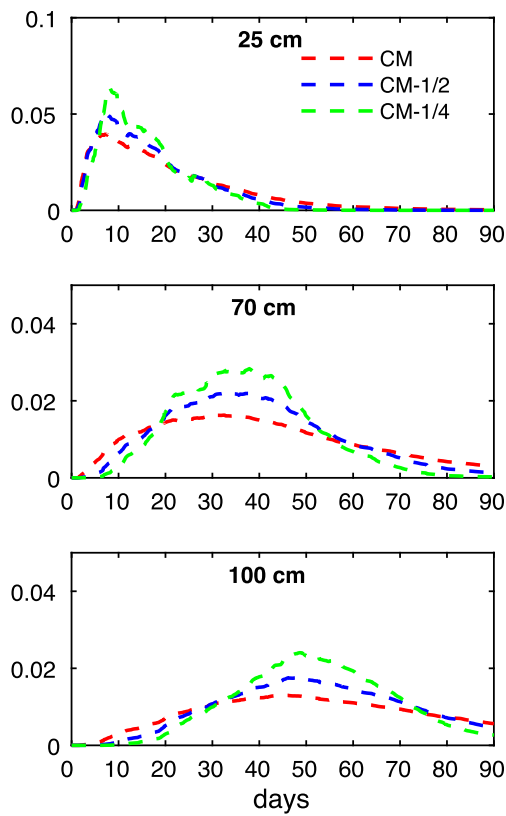

(c)
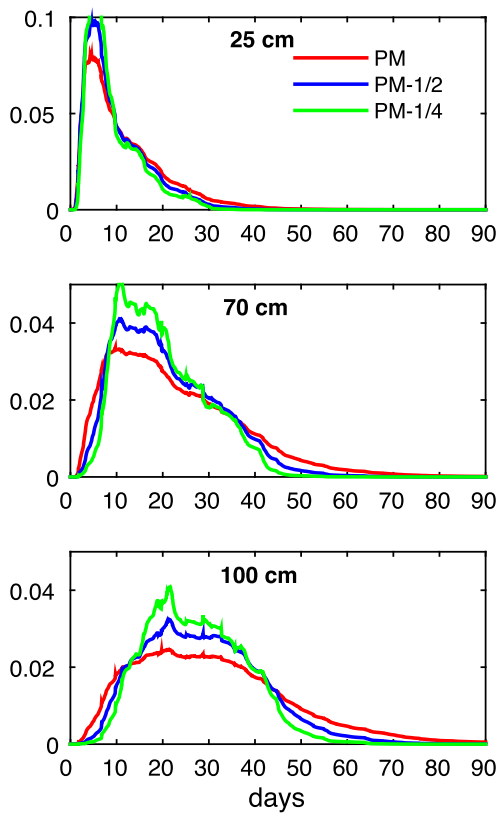

FIG. 5. Soil water transit time distributions for sites A, B and D (red dots in Fig. 3) (a) adapted from MM2010) and estimated from WT-Noah-MP with the (b) CM, CM-1/2 and CM-1/4 scenarios and (c) PM, PM-1/2 and PM-1/4 scenarios.

Figure $4 \mathrm{~b}$ shows the simulation with $b=5.08$ with a better representation than $b=8.52$ (not shown) because a smaller value of $b$ requires larger soil moisture gradients to maintain the quasi-equilibrium soil moisture in wet conditions. This suggests that the model overrepresents the nonlinearity between soil moisture and $K(z)$ with large $b$ values. In addition, the model also underestimates the $100-\mathrm{cm}$ soil moisture in the wet period (after mid-December) when the observed soil moisture was near saturated. This can be attributed to the simplified model physics in Noah-MP that allows free drainage from the soil bottom (with the current configuration) with no lateral flow represented, while the near-saturated soil moisture in Fig. 4a is measured at a location close to slope base (Fig. 3a) as a result of the low permeability of the bedrock and especially of upstream lateral flow. Differences also exist in precipitation forcing from gauge measurements and NLDAS representing a $1 / 8^{\circ}$ grid. Note that tracer transit is a function of flux, storage, and mixing, and we believe that Noah-MP reasonably captures the dynamics of soil moisture that allows us to estimate subsurface transit features.

\section{2) CM SCENARIO}

We now test the hypotheses of tracer mixing in WTNoah-MP using transit time distribution. We do this first for the CM scenario with complete mixing in each of the original seven soil layers. For each tagged event, we obtain the transit time distribution using (9) (Zuber 1986; McGuire et al. 2007):

$$
\operatorname{TTD}(t)=\frac{C_{I}(t)}{\int_{0}^{\infty} C_{I}(t) d t}=C_{I}(t) Q(t) / M
$$

where $\operatorname{TTD}(t)$ is the transit time distribution from the model, $C_{I}(t)$ is the tracer output concentration, $Q(t)$ is the output flux, and $M$ is the sum of tracer mass applied to the system, which is the water mass of the tagged precipitation event in our case. Using this equation, we obtain the transit time distribution at 25-, 70-, and $100-\mathrm{cm}$ depths of each event. Figure $5 \mathrm{~b}$ (red dashed curve) shows the result from WT-Noah-MP. (Note that all the simulations are run with $b=5.08$.) The model results show more lagged and dispersed tracer responses as the tracers infiltrate down the soil column (from the soil surface to deeper soils). Comparing with observations from MM2010 with particular focus on site D (black curves in Fig. 5a), which is the most upstream site (see location in Fig. 3a) and less likely subject to lateral flow, the modeled mean transit times at $70 \mathrm{~cm}$ (38 days) and $100 \mathrm{~cm}$ (55 days) are much longer than the observed ones ( $\sim 22$ days), and the modeled transit time distributions at all levels are more dispersed than observations. Moreover, the time lag of $\sim 10$ days before the 
rising limb seen at the $92-95-\mathrm{cm}$ level is not reproduced in the model. Therefore, the modeled transit times with $\mathrm{CM}$ show more dispersed distribution, longer mean transit time at deeper layers with no time lag of wetfront penetration. These could be an artifact of the complete mixing assumption, which results in too much tracer being retained in the unsaturated soil (McGuire et al. 2007).

\section{3) PM SCENARIO}

Now, we accelerate the water transit through preferential flow paths by assuming half of the soil water storage to be active/mobile, while the other half retained in the soil matrix (see Fig. 1). Figure 5c (red solid curve) shows the modeled transit time distributions of soil water at 25, 70, and $100 \mathrm{~cm}$. Compared with Fig. 5b, the distributions from the PM scenario are more highly peaked with less dispersion. The mean transit times estimated from Fig. 5c (red solid curves) are 10, 22, and 28 days for the three levels, which are very close to the ones estimated from isotope observations (Fig. 5a). The faster transit of tracers can also be seen in Fig. 6, which shows a faster downward propagation of the tracer flow (comparing the red dashed and solid profiles). The better results from the PM-active scenario suggest that the preferential flow pathways are critical for event water transit at WS10, especially for these events after the soil wet-up. However, the observed time lag in the rising limb of the hydrograph of tracer response at $\sim 100 \mathrm{~cm}$ is still not captured.

\section{4) CM-1/2 AND CM-1/4 SCENARIOS}

To better represent the vertical profiles of tracers, we assume mixing in every $1 / 2$ and $1 / 4$ of the original soil thickness for each layer. Figure $5 \mathrm{~b}$ show the modeled transit time distributions from this assumption (dashed blue and green curves). By allowing mixing in a thinner layer, we see more narrow-peaked distributions. Unlike that in the PM scenario, the mean transit times are not significantly changed, but there is a clear lag of the rising limb in tracer response at $100 \mathrm{~cm}$. This lag is explained by a less dispersed downward penetration shown in Fig. 6 (cf. the dashed red, blue, and green profiles). Thus, tracers simulated with CM-1/2 and CM- $1 / 4$ penetrate in a more concentrated way into deeper layers, mimicking piston flow. This enables these scenarios to capture the lag of tracer response in deeper layers, which is not captured by the CM or PM simulations.

\section{5) PM-1/2 AND PM-1/4 SCENARIOS}

Because of the importance of preferential flow through macropores and piston replacement in the soil matrix, we incorporate both partial mixing assumptions of active/mobile storage and vertically constrained mixing into the model. As a result, the simulated transit times in Fig. 5c show less spread-out distributions and lagged rising limbs at deeper levels, both of which are more consistent with those derived from isotopes. In addition, the PW-1/4 modifies the $100-\mathrm{cm}$ recession limb having a similar time as the rising limb, resulting in a better agreement with the isotope-derived ones.

To conclude, we test different hypotheses of mixing in estimating transit times in subsurface water using WTNoah-MP. At WS10, the assumption of complete mixing in unsaturated soil results in broader distributions with longer transit times in deeper soil in stark contrast to the isotope-derived transit times from MM2010. For this case in which wet conditions dominate, we find it critical to represent the tracer transit through both preferential flowpaths and piston displacement. To do this in the model framework, we incorporate a mobile and an immobile soil moisture storage and include additional sublayers in the simulation of the tracer transport.

\section{b. Regional-scale simulation of an extreme precipitation event}

In this section, we apply the WT-Noah-MP tool to better understand an extreme event that affected western Washington. Our goal is to demonstrate that, in addition to watershed applications, WT-Noah-MP can be used as a tool to investigate the water budget and subsurface time scales of a precipitation event with regional-scale impacts. Using the tracers, we tag the precipitation from an extreme precipitation event and track its contribution to different storages and fluxes throughout the terrestrial system.

\section{1) PARTITION OF AR PRECIPITATION INTO DIFFERENT STORES}

WT-Noah-MP can help us better quantify the contribution of this AR to different storages over land. Precipitation that falls on the soil surface can contribute to soil moisture and flooding that causes inundation and direct economic losses, while the precipitation that falls on snowpack might contribute to snow accumulation that is critical for local water resources or rain-on-snow that may trigger snowmelt (Bonne et al. 2015; Guan et al. 2016).

For the date with maximum daily precipitation (from 0000 UTC 3 December to 0000 UTC 4 December 2007), up to $75 \mathrm{~mm}$ of precipitation fell over the Cascade Mountains (red circle in Fig. 7a), while up to $60 \mathrm{~mm}$ fell on the lower coastal lands (blue circle in Fig. 7a). The results derived from WT-Noah-MP clearly reveal that the precipitation over the Cascade Mountains is accumulated as snow water (Fig. $7 b$ ), while that over the 

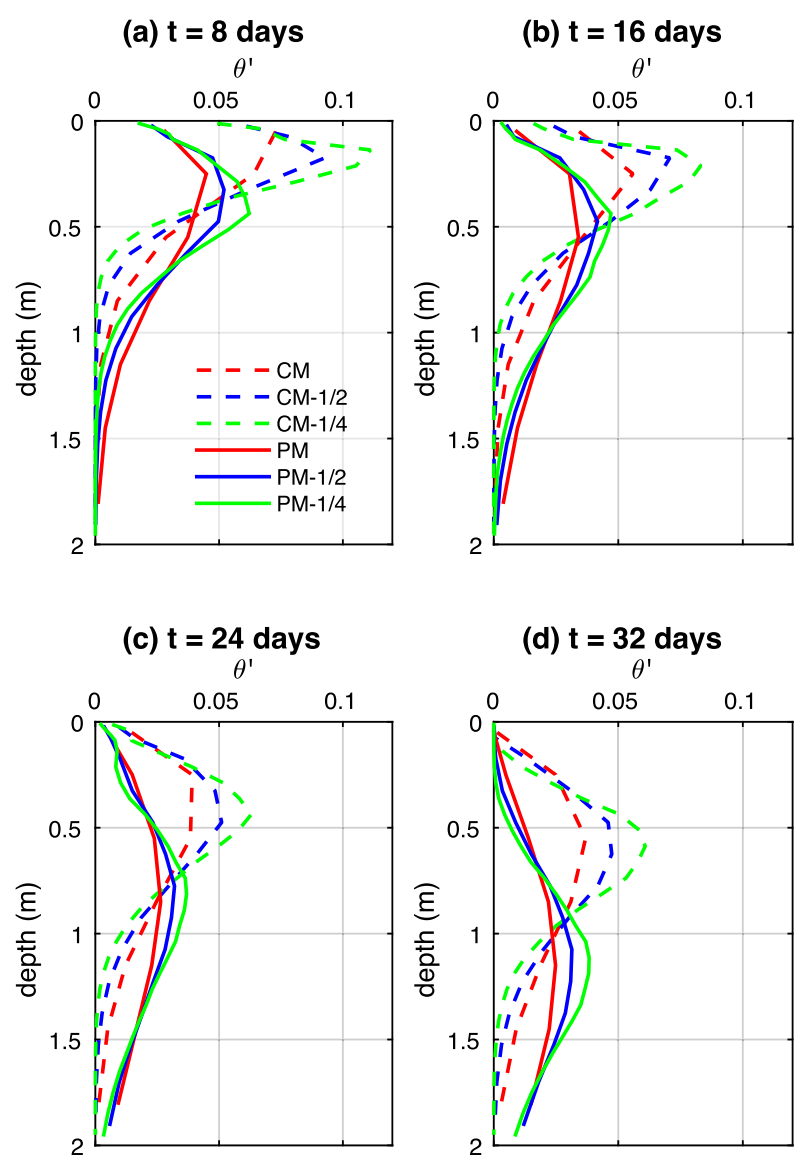

FIG. 6. Averaged tracer soil moisture profiles $\left(\mathrm{m}^{3} \mathrm{~m}^{-3}\right)$ derived from WT-Noah-MP with different scenarios at (a) 8, (b) 16, (c) 24, and (d) 32 days after the tagging initiation of each event.

western lowlands and to the southeast of the Cascades was mostly stored as soil moisture (Fig. 7c). However, the water tracers are revealing a more nuanced picture. If we only look at the changes in total snow accumulation, we see that there were significant loses (blue regions) in the low-elevation regions (Fig. 7d). However, the tracers do not show such significant losses (Fig. 7b). This indicates that there was significant melting of the snow that had accumulated before the AR impacted the region. The melted snow then contributed to total soil moisture (Fig. 7e), but clearly, changes in soil moisture to the southeast of the Cascades were mostly due to "pre-event" water, rather than tagged water (cf. Fig. 7e to Fig. 7c).

Figure $8 \mathrm{~b}$ shows that the total surface runoff is mostly composed of precipitation from this AR event (85.5\%) while the rest $14.5 \%$ is contributed by the snowmelt from antecedent snow. A similar estimation is also obtained by Guan et al. (2016) from the rain-on-snow ARs affecting the southwest coast, with $\sim 20 \%$ of total runoff from snowmelt. It is a key feature usually associated with extreme ARs, which can exaggerate the quick runoff response of basins because they are usually associated with higher temperatures. Therefore, the WTNoah-MP tool helps differentiate the role of this AR in causing the extreme flooding into the precipitation from this event (direct) and the indirect thermal effect that triggered snowmelt across the region. By the end of the tagged period (0000 UTC 10 December 2007), water from the AR event accounts for $>15 \%$ of soil moisture (Fig. 7g) over the low-elevation areas, while snowfall associated with this AR accounts for $>50 \%$ of snow water over the Cascades (Fig. 7f). However, the value of the tracers is perhaps best exemplified when analyzing the tracer water for times after the event has passed.

\section{2) SubSuRfaCE DyNAMICS OF ARS EXTENDING TO THE SEASONAL SCALE}

About $2 / 3$ of this AR's precipitation was stored as soil moisture (Fig. 8a). Upon their arrival, ARs can replenish soil moisture and abruptly end the long-term water deficits between precipitation and evapotranspiration as drought busters (Dettinger 2013). Afterward, these ARs can have hydroclimate impacts with much longer scales than the event time scale (days), by modifying landatmosphere interactions through evapotranspiration and by contributing to subsurface runoff that recharges groundwater and contributes to hydrographs.

From the simulation with $\mathrm{CM}$, the tracers in the soil slowly leave the system as free drainage with a surge in mid-May due to the melting of tracers in snowpack (red dashed line in Fig. 8a). The main outflow is through subsurface runoff while the fluxes through evapotranspiration and surface runoff are comparable and small (Fig. 8a). By 1 July 2007, all of the tracers in snow have melted while more than $50 \%$ of water from this AR's precipitation is still retained in the soil moisture storage, suggesting a longer-than-seasonal time scale transit time of this AR assuming complete mixing.

Including additional sublayers in the soil does not result in large differences of event water stored as soil moisture (cf. CM, CM-1/2, and CM-1/4 in Fig. 9). However, the simulation with PM shows faster transit and thus fewer tracers retained in the soil (red solid line in Figs. 8a and 9). From Fig. 9, the decrease of tracer water in the soil occurs preferentially close to the surface $(0.25$ and $0.85 \mathrm{~m}$ ) after January, while those at $1.45 \mathrm{~m}$ depth have comparable tracer amount from all simulations. As a result, only $\sim 22 \mathrm{~kg} \mathrm{~m}^{-2}$ of water that is from this AR is retained in the soil by 1 July 2008 from the PM simulation. This accounts for $\sim 30 \%$ of the total precipitation from this AR, suggesting that this event can contribute to local transpiration and especially groundwater recharge after 6 months. 
(a)

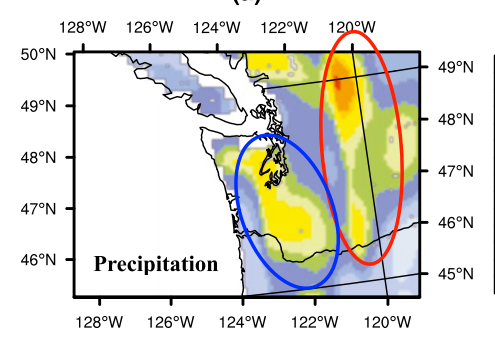

(b)

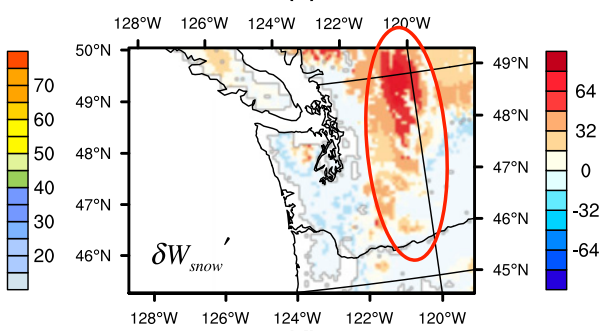

(d)

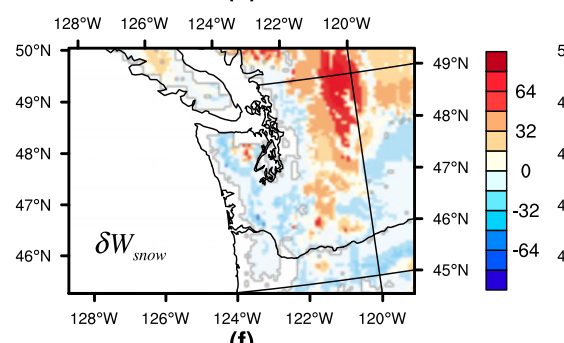

(f)

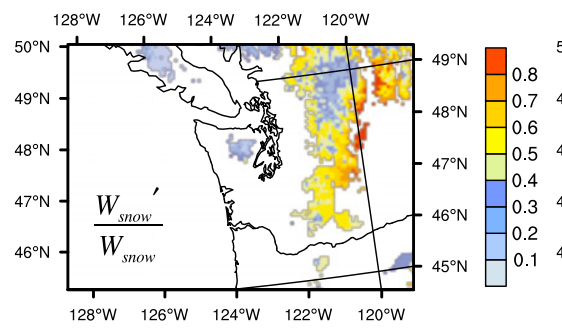

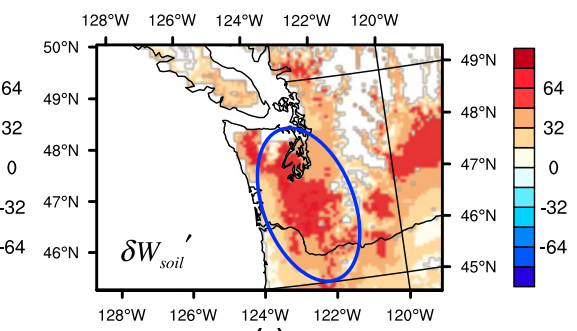

(e)

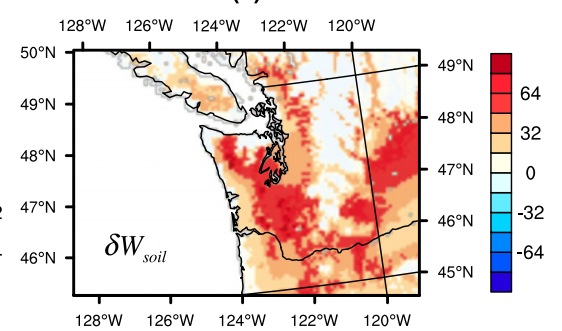

(g)

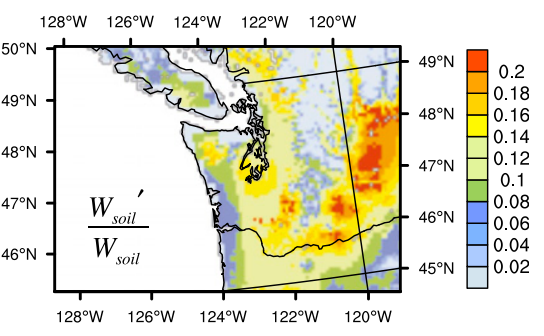

FIG. 7. (a) The precipitation amount $\left(\mathrm{kg} \mathrm{m}^{-2}\right)$ between 0000 UTC 3 Dec and 0000 UTC 4 Dec 2007. (b) The differences of snow water equivalent $\left(\mathrm{kg} \mathrm{m}^{-2}\right)$ derived from tracers between 0000 UTC 3 Dec and 0000 UTC 4 Dec 2007. (c) The differences of soil moisture $\left(\mathrm{kg} \mathrm{m}^{-2}\right)$ derived from tracers between 0000 UTC 3 Dec and 0000 UTC 4 Dec 2007. (d) The differences of total snow water equivalent $\left(\mathrm{kg} \mathrm{m}^{-2}\right)$ derived from original Noah-MP between 0000 UTC 3 Dec and 0000 UTC 4 Dec 2007. (e) The differences of total soil moisture $\left(\mathrm{kg} \mathrm{m}^{-2}\right)$ derived from original Noah-MP between 0000 UTC 3 Dec and 0000 UTC 4 Dec 2007. (f) The ratios of snow water equivalent that is $>50 \mathrm{~kg} \mathrm{~m} \mathrm{~m}^{-2} \mathrm{due}$ to tracers at 0000 UTC $10 \mathrm{Dec} 2007$. (g) The ratios of soil moisture due to tracers at 0000 UTC 10 Dec 2007. All the results are from WT-Noah-MP with the CM scenario.

In summary, we use WT-Noah-MP to track the water that originates as precipitation from an AR event. Of the total surface runoff that significantly contributed to local flooding, $85.5 \%$ came from the precipitation of this AR while the remaining $14.5 \%$ came from the snowmelt from the antecedent snowpack. However, the surface runoff only consists of a small portion of this AR's precipitation. About $2 / 3$ of AR precipitation was stored in the soil immediately after the event, and $\sim 1 / 3$ was stored as snow. During days and months following the event, these stores of water are depleted through runoff or evaporation. The rate at which the water leaves the surface-subsurface system depends on the different mixing assumptions. The CM simulation shows the largest amount of tracers retained in the soil and the slowest transit out, consistent with that in WS10 experiments. In the PM simulation, event water leaves the system at a faster rate through subsurface runoff (see purple line of Fig. 8a), thus depleting soil moisture. The soil moisture conditions before the 3 December event occurred were anomalously wet, as two previous storms had impacted the region in the days leading up to the AR. For this reason, we hypothesize that the PM simulation more realistically captures the transit times in the system. However, without regional-scale observations, we cannot test our hypothesis. For this reason, the $\mathrm{CM}$ and $\mathrm{PM}$ simulations provide an "envelope of uncertainty" regarding the transit time distributions in the basin. Regardless of the assumptions used, approximately $30 \%$ of the AR's precipitation remains in the soil after 6 months. This result allows us to quantify the residence time of this extreme event in the terrestrial hydrologic system.

\section{c. Comments}

In the two examples above, we illustrate the use of WT-Noah-MP to track event-based water in 1) a detailed examination of subsurface transit at the watershed scale and 2) a regional-scale event water budget analysis. Unlike isotope-enabled LSMs, we 

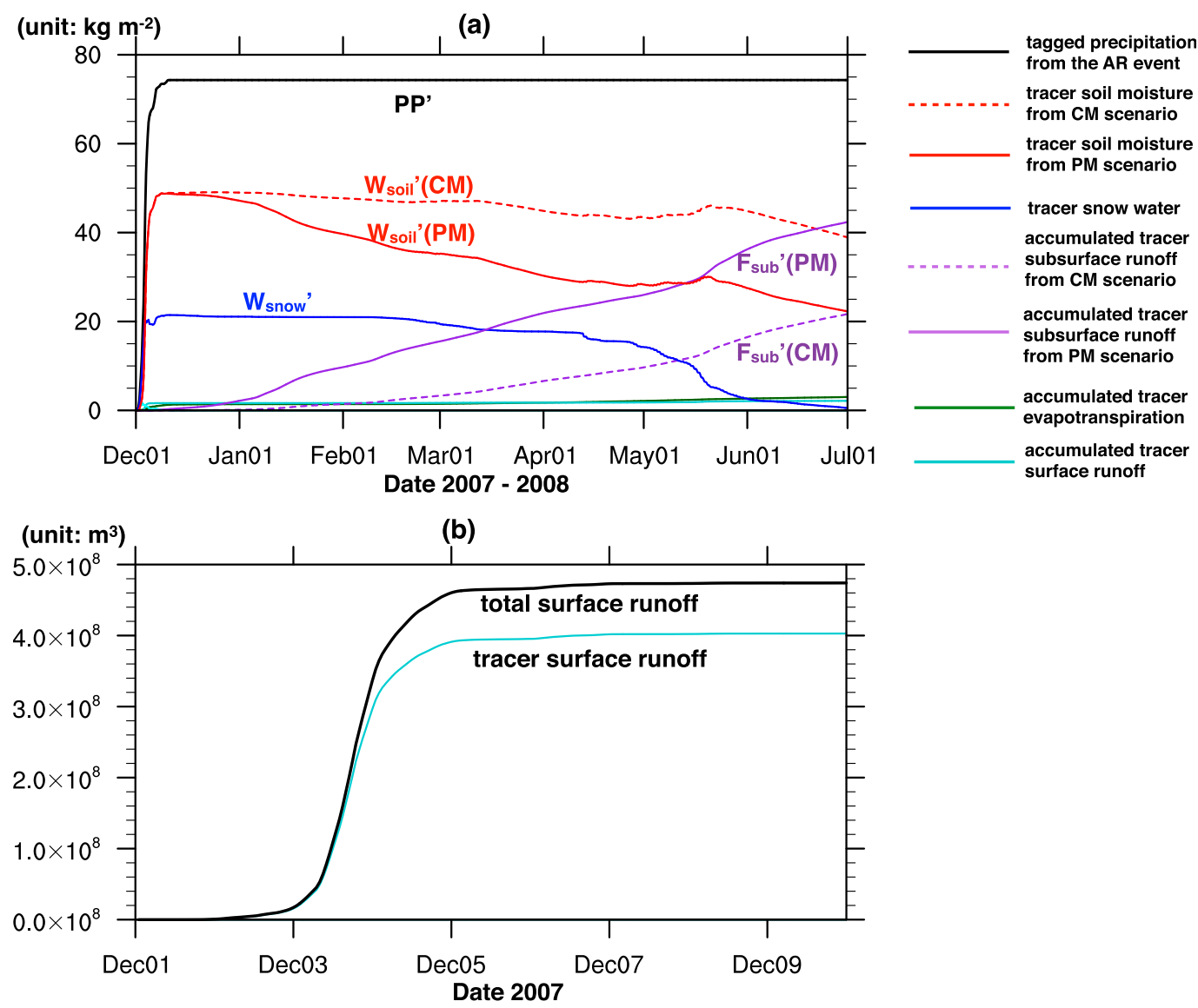

FIG. 8. (a) Time series of domain-averaged tracer fluxes and storages (see labels and legends). (b) Time series of domain-aggregated surface runoff (solid black) and tracer surface runoff (solid turquoise) accumulated from 0000 UTC 1 Dec to 0000 UTC 10 Dec 2007.

trace the total event-based water and not the isotopes. For this reason, no isotopic data are required to drive the tracer module because we only need the total water amount from the tagged event as tracer input. These data can be derived from the forcing (precipitation) used to drive any regular LSM. Since we are tracing the actual water, no fractionation process needs to be included, reducing the uncertainty and making the interpretation more straightforward. For these reasons, the new numerical water tracer tool makes it possible to investigate event-based physical processes in a wide range of spatial and temporal scales.

However, we still require isotope observations to validate our results. In our application to WS10, the isotope data collected from field experiments and its derived transit time distribution by MM2010 become a key benchmark to test the mixing assumptions that allow different subsurface flow regimes. Because the water tracer model does not provide isotope data, we convert the tracer results into transit times. On the other hand, the output from an isotope-enabled LSM would be directly comparable to isotope observations. It is clear that, while the goal of numerical water tracers in LSMs and isotope-enabled LSMs is similar-to track the movement of water through the surface-subsurface modeling system-each tool has its own strengths and weaknesses (see Table 4). The two methods can be used as complementary tools to track water through the terrestrial system.

When compared with isotopic observations, WTNoah-MP is a powerful tool that can provide a critical test for the physical processes represented in the model. As an example, isotope observations have shown that plants uptake water from different soil depths (e.g., Ehleringer and Dawson 1992), and WT-Noah-MP can be used to evaluate if the model is appropriately representing plant water uptake depth. More generally, isotopic studies have identified an ecohydrological separation of soil water: the water transpired from plants is different from water that contributes to streamflow (Brooks et al. 2010; Evaristo et al. 2015). Water tracers can be used as a tool to improve LSMs, so they better represent these 

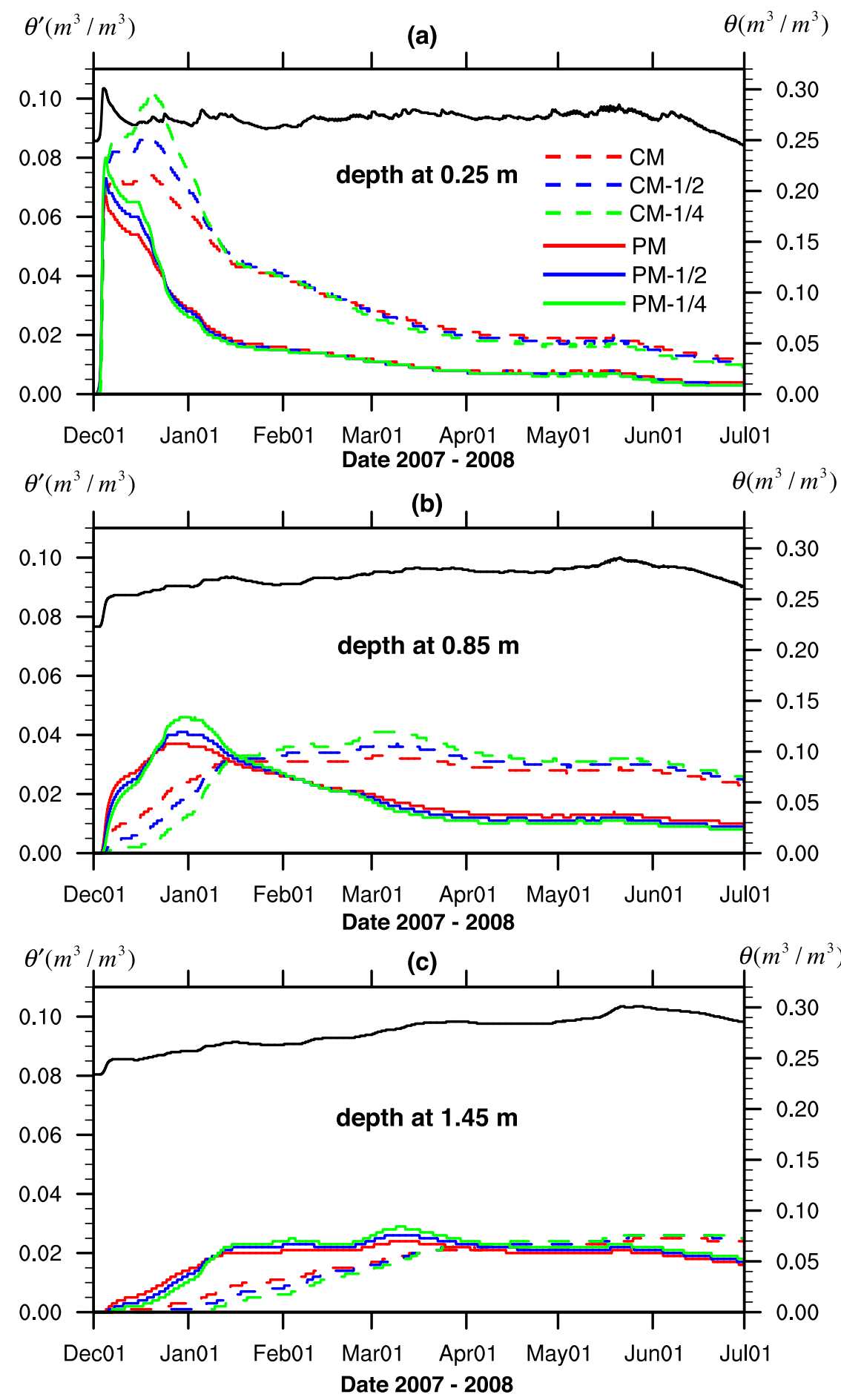

FIG. 9. WT-Noah-MP simulated soil moisture at (a) 0.25-, (b) 0.85-, and (c) 1.45-m depths. The colored curves show the tracer soil moisture [see legend in (a)] paired with the $y$ axis on the left, while the black curves show the total soil moisture paired with the $y$ axis on the right.

compartments. Isotopic studies are critical for understanding the water cycle and the linked ecological processes (Good et al. 2015), but in general, LSMs have lagged far behind the isotopic observations. WT-Noah-
MP and the existing isotope-enabled models can help bridge the gap between the observations and models.

It is important to clarify that, because of the simple runoff scheme of our simulations, water leaves the 
TABLE 4. Comparison of the two tracer tools in LSMs.

\begin{tabular}{lcc}
\hline \hline & \multicolumn{1}{c}{ Stable water isotope tracers } & Numerical water tracers \\
\hline Tracking objective & Compositions of ${ }^{1} \mathrm{H}^{2} \mathrm{H}^{16} \mathrm{O}$ and ${ }^{1} \mathrm{H}_{2}{ }^{18} \mathrm{O}$ & $\begin{array}{c}\text { Total amount of water sourced from a } \\
\text { precipitation event (event water) }\end{array}$ \\
Similarities & $\begin{array}{c}\text { Track the movement of water molecules in LSM and reveal the characteristics of different processes } \\
\text { parameterized by the model (diagnostic tools for model's performance) }\end{array}$ \\
Differences & $\begin{array}{c}\text { Provide a seamless interface with isotope observations } \\
\text { - Help interpret isotopic signals in association with } \\
\text { climate variation and climate changes in the past }\end{array}$ & $\begin{array}{c}\text { No isotope data are required to drive the } \\
\text { tracer module }\end{array}$ \\
& $\begin{array}{c}\text { No deconvolution/inversion is required to } \\
\text { interpret the result }\end{array}$ \\
& & $\bullet$ No fractioning parameterization \\
\hline
\end{tabular}

bottom soil layer as free drainage. Thus, we are not able to resolve the effect of bedrock permeability that is one of the main geological controls on catchment transit times (Hale and McDonnell 2016; Pfister et al. 2017). In addition, Noah-MP does not take the vertical variation of saturated hydraulic conductivity into account. Both of these processes contribute to the dry bias of soil moisture in deeper layers at WS10 and are likely to affect the estimation of transit times. Furthermore, the partitioning of half of the storage to be active/mobile is arbitrary and could be improved by parameterizing it as a function of soil moisture (e.g., Fenicia et al. 2010; Hrachowitz et al. 2013). These could be subjects to be improved in the future.

\section{Conclusions}

We have presented a new water tracer tool specifically designed to track individual hydrometeorological events-shifting the LSM approach from a bulk estimation of storages and fluxes to an explicit representation of event water transit. We implement this numerical water tracer scheme in Noah-MP (WT-Noah-MP). The new numerical water tracers tag the total water from precipitation events of interest and track the subsequent partitioning and movement in the surface-subsurface continuum. In comparison to existing LSMs that incorporate isotopes, our water tracer tool does not require isotopic information as either initial conditions or boundary forcing, nor does it require the parameterization of isotopic fractionation processes. We believe WT-NoahMP is complementary to existing isotope-enabled LSMs. The new water tracer tool allows for a long-term tracking of specific precipitation events and a straightforward interpretation of hydrological processes. Noah-MP is the first LSM with this numerical water tracer capability.

In the tracer implementation, we make particular efforts to appropriately account for horizontal and vertical heterogeneity in mixing during subsurface transit. This is necessary because the complete mixing assumption (CM) usually causes an artificially long transit time. Therefore, to account for tracer transit through preferential flow pathways, which would usually result in a faster transit and is critical for wet soil conditions, we approximate the mixing and transfer of tracers only occurring in the part of storage that is active/mobile. In this study, we test this approximation by specifying half of the total storage to be active/mobile (PM). In addition, to better preserve the tracer penetration as piston flow in the soil matrix, we discretize thinner soil layers for mixing, so that tracers can percolate with less dispersion. We test this assumption by allowing mixing in $1 / 2$ and $1 / 4$ of each original soil layer (PM-1/2 and PM-1/4).

The different mixing assumptions are tested in a well-studied watershed WS10 in Oregon over a period after soil wet-up. Comparing the transit times estimated from our water tracer tool and those from isotopic measurements (MM2010), the PM run significantly improves the transit time estimations in deeper soils (70 and $100 \mathrm{~cm}$ ) when compared to the unrealistically longer transit times in the CM simulation. The PM-1/2 and PM-1/4 estimations further improve the transit time distributions, suggesting a more realistic tracer transit taking both preferential flow and piston flow into account, especially under wet soil conditions. We then use WT-Noah-MP to investigate the effect of an extreme AR event in December 2007 over western Washington. While the CM simulation shows that most of the tracers are retained in the soil until July 2008, perhaps a more realistic estimation comes from the PM simulation with a faster transit of tracers and $\sim 30 \%$ of this AR's total precipitation retained in the soil by July 2008. This event water retained in the soil can contribute to local evapotranspiration, groundwater recharge, and base flow. Above the soil, we use WT-Noah-MP to differentiate and quantify the direct (runoff from this AR's precipitation) and indirect (snowmelt trigged by the warm feature of this AR) effects to flooding, which are difficult to derive from the original Noah-MP but simple to understand using the tracers. This additional information is valuable because 
it helps anticipate possible changes of ARs' hydrologic consequences based on antecedent snow conditions and thermodynamic changes.

Acknowledgments. Support for this study has been provided in part by the National Aeronautics and Space Administration (NASA) Grant NNX14AD77G, the National Science Foundation (NSF) Grant 1454089, and the Graduate Student Visitor Program from the National Center for Atmospheric Research (NCAR) Advanced Study Program. We thank Michael Barlage and Wei $\mathrm{Yu}$ at NCAR for their assistance of coding. We also thank Kevin McGuire for assistance with WS10 observational data and figure. Any opinions, findings, and conclusions or recommendations expressed in this publication are those of the authors and do not necessarily reflect the views of NASA, NSF, or NCAR.

\section{REFERENCES}

Aleinov, I., and G. A. Schmidt, 2006: Water isotopes in the GISS ModelE land surface scheme. Global Planet. Change, 51, 108-120, https://doi.org/10.1016/j.gloplacha.2005.12.010.

Allen, S. T., J. R. Brooks, R. F. Keim, B. J. Bond, and J. J. McDonnell, 2014: The role of pre-event canopy storage in throughfall and stemflow by using isotopic tracers. Ecohydrology, 7, 858-868, https://doi.org/10.1002/eco.1408.

Barlage, M., M. Tewari, F. Chen, G. Miguez-Macho, Z.-L. Yang, and G.-Y. Niu, 2015: The effect of groundwater interaction in North American regional climate simulations with WRF/Noah-MP. Climatic Change, 129, 485-498, https:// doi.org/10.1007/s10584-014-1308-8.

Birkel, C., C. Soulsby, D. Tetzlaff, S. Dunn, and L. Spezia, 2012: High-frequency storm event isotope sampling reveals timevariant transit time distributions and influence of diurnal cycles. Hydrol. Processes, 26, 308-316, https://doi.org/10.1002/ hyp. 8210 .

Bonne, J.-L., and Coauthors, 2015: The summer 2012 Greenland heat wave: In situ and remote sensing observations of water vapor isotopic composition during an atmospheric river event. J. Geophys. Res. Atmos., 120, 2970-2989, https://doi.org/ 10.1002/2014JD022602.

Braud, I., T. Bariac, J. P. Gaudet, and M. Vauclin, 2005: SiSPATIsotope, a coupled heat, water and stable isotope (HDO and H218O) transport model for bare soil. Part I. Model description and first verifications. J. Hydrol., 309, 277-300, https:// doi.org/10.1016/j.jhydrol.2004.12.013.

Brooks, J. R., H. R. Barnard, R. Coulombe, and J. J. McDonnell, 2010: Ecohydrologic separation of water between trees and streams in a Mediterranean climate. Nat. Geosci., 3, 100-104, https://doi.org/10.1038/ngeo722.

Buttle, J. M., 1994: Isotope hydrograph separations and rapid delivery of pre-event water from drainage basins. Prog. Phys. Geogr., 18, 16-41, https://doi.org/10.1177/030913339401800102.

— preferential flow on a forested slope. Water Resour. Res, $\mathbf{3 8}$, 1060, https://doi.org/10.1029/2001WR000773.

Cai, X., Z.-L. Yang, C. H. David, G.-Y. Niu, and M. Rodell, 2014: Hydrological evaluation of the Noah-MP land surface model for the Mississippi River Basin. J. Geophys. Res. Atmos., 119, 23-38, https://doi.org/10.1002/2013JD020792.

Carlyle-Moses, D. E., and J. H. C. Gash, 2011: Rainfall interception loss by forest canopies. Forest Hydrology and Biogeochemistry, Ecological Studies Series, Vol. 216, Springer, 407-423, https:// doi.org/10.1007/978-94-007-1363-5_20.

Clapp, R. B., and G. M. Hornberger, 1978: Empirical equations for some soil hydraulic properties. Water Resour. Res., 14, 601-604, https://doi.org/10.1029/WR014i004p00601.

Dettinger, M. D., 2013: Atmospheric rivers as drought busters on the U.S. West Coast. J. Hydrometeor., 14, 1721-1732, https:// doi.org/10.1175/JHM-D-13-02.1.

Ehleringer, J. R., and T. E. Dawson, 1992: Water uptake by plants: Perspectives from stable isotope composition. Plant Cell Environ., 15, 1073-1082, https://doi.org/10.1111/j.13653040.1992.tb01657.x.

Ek, M. B., K. E. Mitchell, Y. Lin, E. Rogers, P. Grunmann, V. Koren, G. Gayno, and J. D. Tarpley, 2003: Implementation of Noah land surface model advances in the National Centers for Environmental Prediction operational mesoscale Eta model. J. Geophys. Res., 108, 8851, https://doi.org/10.1029/2002JD003296.

Evaristo, J., S. Jasechko, and J. J. McDonnell, 2015: Global separation of plant transpiration from groundwater and streamflow. Nature, 525, 91-94, https://doi.org/10.1038/nature14983.

Feng, X., S. Taylor, C. E. Renshaw, and J. W. Kirchner, 2002: Isotopic evolution of snowmelt: 1 . A physically based onedimensional model. Water Resour. Res, 38, 1217, https:// doi.org/10.1029/2001WR000814.

Fenicia, F., S. Wrede, D. Kavetski, L. Pfister, L. Hoffmann, H. H. G. Savenije, and J. J. McDonnell, 2010: Assessing the impact of mixing assumptions on the estimation of streamwater mean residence time. Hydrol. Processes, 24, 1730-1741, https://doi.org/10.1002/hyp.7595.

Fischer, M. J., 2006: iCHASM, a flexible land-surface model that incorporates stable water isotopes. Global Planet. Change, 51, 121-130, https://doi.org/10.1016/j.gloplacha.2005.12.008.

—_, and K. Sturm, 2006: REMOiso forcing for the iPILPS Phase 1 experiments and the performance of REMOiso in three domains. Global Planet. Change, 51, 73-89, https:// doi.org/10.1016/j.gloplacha.2005.12.006.

Gat, J. R., 1996: Oxygen and hydrogen isotopes in the hydrologic cycle. Annu. Rev. Earth Planet. Sci., 24, 225-262, https:// doi.org/10.1146/annurev.earth.24.1.225.

Genereux, D. P., and R. P. Hooper, 1998: Oxygen and hydrogen isotopes in rainfall-runoff studies. Isotope Tracers in Catchment Hydrology, Elsevier, 319-346.

Gerdel, R. W., 1954: The transmission of water through snow. Eos, Trans. Amer. Geophys. Union, 35, 475-485, https://doi.org/ 10.1029/TR035i003p00475.

Gochis, D. J., W. Yu, and D. N. Yates, 2013: The WRF-Hydro model technical description and user's guide, version 1.0. NCAR Tech. Doc., 120 pp., https://www.ral.ucar.edu/projects/wrf_hydro.

Godsey, S. E., J. W. Kirchner, and D. W. Clow, 2009: Concentration-discharge relationships reflect chemostatic characteristics of US catchments. Hydrol. Processes, 23, 1844-1864, https:// doi.org/10.1002/hyp.7315.

Good, S. P., D. Noone, and G. Bowen, 2015: Hydrologic connectivity constrains partitioning of global terrestrial water fluxes. Science, 349, 175-177, https://doi.org/10.1126/science.aaa5931.

Guan, B., D. E. Waliser, F. M. Ralph, E. J. Fetzer, and P. J. Neiman, 2016: Hydrometeorological characteristics of rain-on-snow events associated with atmospheric rivers. Geophys. Res. Lett., 43, 2964-2973, https://doi.org/10.1002/2016GL067978. 
Haese, B., M. Werner, and G. Lohmann, 2013: Stable water isotopes in the coupled atmosphere-land surface model ECHAM5-JSBACH. Geosci. Model Dev., 6, 1463-1480, https:// doi.org/10.5194/gmd-6-1463-2013.

Hale, V. C., and J. J. McDonnell, 2016: Effect of bedrock permeability on stream base flow mean transit time scaling relations: 1. A multiscale catchment intercomparison. Water Resour. Res., 52, 1358-1374, https://doi.org/10.1002/ 2014WR016124.

Henderson-Sellers, A., 2006: Improving land-surface parameterization schemes using stable water isotopes: Introducing the 'iPILPS' initiative. Global Planet. Change, 51, 3-24, https:// doi.org/10.1016/j.gloplacha.2005.12.009.

Hrachowitz, M., C. Soulsby, D. Tetzlaff, J. J. C. Dawson, S. M. Dunn, and I. A. Malcolm, 2009: Using long-term data sets to understand transit times in contrasting headwater catchments. J. Hydrol., 367, 237-248, https://doi.org/10.1016/j.jhydrol.2009.01.001.

- - H. Savenije, T. A. Bogaard, D. Tetzlaff, and C. Soulsby, 2013: What can flux tracking teach us about water age distribution patterns and their temporal dynamics? Hydrol. Earth Syst. Sci., 17, 533-564, https://doi.org/10.5194/ hess-17-533-2013.

— , P. Benettin, B. M. van Breukelen, O. Fovet, N. J. K. Howden, L. Ruiz, Y. van der Velde, and A. J. Wade, 2016: Transit timesthe link between hydrology and water quality at the catchment scale. Wiley Interdiscip. Rev.: Water, 3, 629-657, https:// doi.org/10.1002/wat2.1155.

Jones, J. A., 2000: Hydrologic processes and peak discharge response to forest removal, regrowth, and roads in 10 small experimental basins, western Cascades, Oregon. Water Resour. Res., 36, 2621-2642, https://doi.org/10.1029/2000WR900105.

Judy, C., J. R. Meiman, and I. Friedman, 1970: Deuterium variations in an annual snowpack. Water Resour. Res., 6, 125-129, https://doi.org/10.1029/WR006i001p00125.

Kendall, C., and J. J. McDonnell, 1998: Isotope Tracers in Catchment Hydrology. Elsevier, 839 pp., https://doi.org/10.1016/ C2009-0-10239-8.

— terium in river waters across the United States. Hydrol. Processes, 15, 1363-1393, https://doi.org/10.1002/hyp.217.

Klaus, J., and J. J. McDonnell, 2013: Hydrograph separation using stable isotopes: Review and evaluation. J. Hydrol., 505, 47-64, https://doi.org/10.1016/j.jhydrol.2013.09.006.

—, K. P. Chun, K. J. McGuire, and J. J. McDonnell, 2015: Temporal dynamics of catchment transit times from stable isotope data. Water Resour. Res., 51, 4208-4223, https:// doi.org/10.1002/2014WR016247.

Leaney, F. W., K. Smettem, and D. J. Chittleborough, 1993: Estimating the contribution of preferential flow to subsurface runoff from a hillslope using deuterium and chloride. J. Hydrol., 147, 83-103, https://doi.org/10.1016/0022-1694(93)90076-L.

Lee, J., X. Feng, A. Faiia, E. Posmentier, R. Osterhuber, and J. Kirchner, 2010: Isotopic evolution of snowmelt: A new model incorporating mobile and immobile water. Water Resour. Res., 46, W11512, https://doi.org/10.1029/2009WR008306.

Marsh, P., and M. K. Woo, 1984: Wetting front advance and freezing of meltwater within a snow cover: 2. A simulation model. Water Resour. Res., 20, 1865-1874, https://doi.org/ 10.1029/WR020i012p01865.

Martinez, J. A., F. Dominguez, and G. Miguez-Macho, 2016: Impacts of a groundwater scheme on hydroclimatological conditions over southern South America. J. Hydrometeor., 17, 2959-2978, https://doi.org/10.1175/JHM-D-16-0052.1.
McDonnell, J. J., 1990: A rationale for old water discharge through macropores in a steep, humid catchment. Water Resour. Res., 26, 2821-2832, https://doi.org/10.1029/WR026i011p02821.

_ 2017: Beyond the water balance. Nat. Geosci., 10, 396-396, https://doi.org/10.1038/ngeo2964.

— , and K. Beven, 2014: Debates-The future of hydrological sciences: A (common) path forward? A call to action aimed at understanding velocities, celerities and residence time distributions of the headwater hydrograph. Water Resour. Res., 50, 5342-5350, https://doi.org/10.1002/2013WR015141.

McGuire, K. J., and J. J. McDonnell, 2006: A review and evaluation of catchment transit time modeling. J. Hydrol., 330, 543-563, https://doi.org/10.1016/j.jhydrol.2006.04.020.

$\longrightarrow$, and _ 2010: Hydrological connectivity of hillslopes and streams: Characteristic time scales and nonlinearities. Water Resour. Res., 46, W10543, https://doi.org/10.1029/2010WR009341.

_ D. R. DeWalle, and W. J. Gburek, 2002: Evaluation of mean residence time in subsurface waters using oxygen-18 fluctuations during drought conditions in the mid-Appalachians. J. Hydrol., 261, 132-149, https://doi.org/10.1016/S0022-1694 (02)00006-9.

_ J. J. McDonnell, M. Weiler, C. Kendall, B. L. McGlynn, J. M. Welker, and J. Seibert, 2005: The role of topography on catchment-scale water residence time. Water Resour. Res., 41, W05002, https://doi.org/10.1029/2004WR003657.

—, M. Weiler, and J. J. McDonnell, 2007: Integrating tracer experiments with modeling to assess runoff processes and water transit times. Adv. Water Resour., 30, 824-837, https:// doi.org/10.1016/j.advwatres.2006.07.004.

Mitchell, K. E., 2004: The multi-institution North American Land Data Assimilation System (NLDAS): Utilizing multiple GCIP products and partners in a continental distributed hydrological modeling system. J. Geophys. Res., 109, D07S90, https:// doi.org/10.1029/2003JD003823.

Neiman, P. J., F. M. Ralph, G. A. Wick, J. D. Lundquist, and M. D. Dettinger, 2008: Meteorological characteristics and overland precipitation impacts of atmospheric rivers affecting the West Coast of North America based on eight years of SSM/I satellite observations. J. Hydrometeor., 9, 22-47, https:// doi.org/10.1175/2007JHM855.1.

Niu, G.-Y., and Coauthors, 2011: The community Noah land surface model with multiparameterization options (Noah-MP): 1. Model description and evaluation with local-scale measurements. J. Geophys. Res., 116, D12109, https://doi.org/10.1029/ 2010JD015139.

NWS, 2008: Service assessment: Pacific Northwest Storms of December 1-3, 2007. NOAA/NWS, 39 pp., https://www. weather.gov/media/publications/assessments/pac_nw08.pdf.

Pfister, L., N. Martínez-Carreras, C. Hissler, J. Klaus, G. E. Carrer, M. K. Stewart, and J. J. McDonnell, 2017: Bedrock geology controls on catchment storage, mixing, and release: A comparative analysis of 16 nested catchments. Hydrol. Processes, 31, 1828-1845, https://doi.org/10.1002/hyp.11134.

Pilotto, I. L., D. A. Rodríguez, J. Tomasella, G. Sampaio, and S. C. Chou, 2015: Comparisons of the Noah-MP land surface model simulations with measurements of forest and crop sites in Amazonia. Meteor. Atmos. Phys., 127, 711-723, https:// doi.org/10.1007/s00703-015-0399-8.

Raben, P., and W. H. Theakstone, 1998: Changes of ionic and oxygen isotopic composition of the snowpack at the Glacier Austre Okstindbreen, Norway, 1995. Hydrol. Res., 29, 1-20.

Ralph, F. M., and M. D. Dettinger, 2012: Historical and national perspectives on extreme West Coast precipitation associated with 
atmospheric rivers during December 2010. Bull. Amer. Meteor. Soc., 93, 783-790, https://doi.org/10.1175/BAMS-D-11-00188.1.

Ranken, D. W., 1974: Hydrologic properties of soil and subsoil on a steep, forested slope. M.S. thesis, Dept. of Forest Engineering, Oregon State University, 127 pp., https://ir.library.oregonstate.edu/ concern/graduate_thesis_or_dissertations/qn59q6026.

Riley, W. J., C. J. Still, M. S. Torn, and J. A. Berry, 2002: A mechanistic model of $\mathrm{H}_{2}^{18} \mathrm{O}$ and $\mathrm{C}^{18} \mathrm{OO}$ fluxes between ecosystems and the atmosphere: Model description and sensitivity analyses. Global Biogeochem. Cycles, 16, 1095, https://doi.org/ 10.1029/2002GB001878.

Risi, C., and Coauthors, 2016: The water isotopic version of the land-surface model ORCHIDEE: Implementation, evaluation, sensitivity to hydrological parameters. Hydrol. Curr. Res., 7, 258, https://doi.org/10.4172/2157-7587.1000258.

Rodell, M., and Coauthors, 2004: The Global Land Data Assimilation System. Bull. Amer. Meteor. Soc., 85, 381-394, https:// doi.org/10.1175/BAMS-85-3-381.

Rouxel, M., J. Molénat, L. Ruiz, C. Legout, M. Faucheux, and C. Gascuel-Odoux, 2011: Seasonal and spatial variation in groundwater quality along the hillslope of an agricultural research catchment (western France). Hydrol. Processes, 25, 831-841, https://doi.org/10.1002/hyp.7862.

Rutz, J. J., W. J. Steenburgh, and F. M. Ralph, 2014: Climatological characteristics of atmospheric rivers and their inland penetration over the western United States. Mon. Wea. Rev., 142, 905-921, https://doi.org/10.1175/MWR-D-13-00168.1.

Sakaguchi, K., and X. Zeng, 2009: Effects of soil wetness, plant litter, and under-canopy atmospheric stability on ground evaporation in the Community Land Model (CLM3.5). J. Geophys. Res, 114, D01107, https://doi.org/10.1029/2008JD010834.

Schaake, J. C., V. I. Koren, Q. Y. Duan, K. Mitchell, and F. Chen, 1996: Simple water balance model for estimating runoff at different spatial and temporal scales. J. Geophys. Res., 101, 7461-7475, https://doi.org/10.1029/95JD02892.

Senatore, A., G. Mendicino, D. J. Gochis, W. Yu, D. N. Yates, and H. Kunstmann, 2015: Fully coupled atmosphere-hydrology simulations for the central Mediterranean: Impact of enhanced hydrological parameterization for short and long time scales. J. Adv. Model. Earth Syst., 7, 1693-1715, https://doi.org/ 10.1002/2015MS000510.

Sklash, M. G., R. N. Farvolden, and P. Fritz, 1976: A conceptual model of watershed response to rainfall, developed through the use of oxygen-18 as a natural tracer. Can. J. Earth Sci., 13, 271-283, https://doi.org/10.1139/e76-029.
Stewart, M. K., and J. J. McDonnell, 1991: Modeling base flow soil water residence times from deuterium concentrations. Water Resour. Res., 27, 2681-2693, https://doi.org/10.1029/91WR01569.

Stichler, W., 1987: Snowcover and snowmelt processes studied by means of environmental isotopes. Seasonal Snowcovers: Physics, Chemistry, Hydrology, Springer, 673-726.

Sturm, C., Q. Zhang, and D. Noone, 2010: An introduction to stable water isotopes in climate models: Benefits of forward proxy modelling for paleoclimatology. Climate Past, 6, 115-129, https://doi.org/10.5194/cp-6-115-2010.

Twining, J., D. Stone, C. Tadros, A. Henderson-Sellers, and A. Williams, 2006: Moisture Isotopes in the Biosphere and Atmosphere (MIBA) in Australia: A priori estimates and preliminary observations of stable water isotopes in soil, plant and vapour for the Tumbarumba Field Campaign. Global Planet. Change, 51, 59-72, https://doi.org/10.1016/ j.gloplacha.2005.12.005.

van der Velde, Y., P. J. J. F. Torfs, S. E. A. T. M. van der Zee, and R. Uijlenhoet, 2012: Quantifying catchment-scale mixing and its effect on time-varying travel time distributions. Water Resour. Res., 48, W06536, https://doi.org/10.1029/2011WR011310.

Weiler, M., and J. McDonnell, 2004: Virtual experiments: A new approach for improving process conceptualization in hillslope hydrology. J. Hydrol., 285, 3-18, https://doi.org/ 10.1016/S0022-1694(03)00271-3.

Yang, Z.-L., and Coauthors, 2011: The community Noah land surface model with multiparameterization options (NoahMP): 2. Evaluation over global river basins. J. Geophys. Res., 116, D12110, https://doi.org/10.1029/2010JD015140.

Yoshimura, K., S. Miyazaki, S. Kanae, and T. Oki, 2006: Iso-MATSIRO, a land surface model that incorporates stable water isotopes. Global Planet. Change, 51, 90-107, https:// doi.org/10.1016/j.gloplacha.2005.12.007.

Zhang, X.-P., Z.-L. Yang, G.-Y. Niu, and X.-Y. Wang, 2009: Stable water isotope simulation in different reservoirs of Manaus, Brazil, by Community Land Model incorporating stable isotopic effect. Int. J. Climatol., 29, 619-628, https:// doi.org/10.1002/joc.1740.

Zhu, Y., and R. E. Newell, 1998: A proposed algorithm for moisture fluxes from atmospheric rivers. Mon. Wea. Rev., 126, 725-735, https://doi.org/10.1175/1520-0493(1998)126<0725: APAFMF $>2.0 . \mathrm{CO} ; 2$.

Zuber, A., 1986: On the interpretation of tracer data in variable flow systems. J. Hydrol., 86, 45-57, https://doi.org/10.1016/ 0022-1694(86)90005-3. 